\title{
Silencing branched-chain ketoacid dehydrogenase or treatment with branched-chain ketoacids ex vivo inhibits muscle insulin signaling \\ Running title: BCKAs impair insulin signaling
}

Dipsikha Biswas $^{1}, \mathrm{PhD}$, Khoi T. Dao ${ }^{1}$, BSc, Angella Mercer ${ }^{1}$, BSc, Andrew Cowie ${ }^{1}$, BSc, Luke Duffley ${ }^{1}$, BSc, Yassine El Hiani ${ }^{2}$, PhD, Petra C. Kienesberger ${ }^{1}, \mathrm{PhD}$, Thomas Pulinilkunnil ${ }^{1 \dagger}, \mathrm{PhD}$

${ }^{1}$ Department of Biochemistry and Molecular Biology, Dalhousie Medicine New Brunswick, Saint John, New

Brunswick, Canada, ${ }^{2}$ Department of Physiology and Biophysics, Dalhousie University, Halifax, Nova Scotia, Canada.

${ }^{\dagger}$ Correspondence to Thomas Pulinilkunnil, $\mathrm{PhD}$

Department of Biochemistry and Molecular Biology, Faculty of Medicine, Dalhousie University Dalhousie Medicine New Brunswick, 100 Tucker Park Road, Saint John E2L4L5, New Brunswick, Canada.

Telephone: (506) 636-6973; Fax: (506) 636-6001; email: tpulinil@dal.ca. 


\begin{abstract}
Abbreviations
Acadm, Acyl-Coenzyme A dehydrogenase, medium chain; BCAAs, branched-chain amino acids; BCKAs, branched-chain keto acids; BCATm, mitochondrial branched chain aminotransferase; BCKDH, branchedchain $\alpha$-keto acid dehydrogenase; BCKDK, branched-chain keto acid dehydrogenase kinase; BT2, 3,6dichlorobenzo [b]thiophene-2-carboxylic acid; Cyclo, Cyclophilin; DIO, diet induced obesity; Glut, glucose transporter; Hadh, Hydroxyacyl-Coenzyme A dehydrogenase; HFD, high fat diet; HFHS, high fat high sucrose diet; Hmgcs1, 3-hydroxy-3-methylglutaryl-Coenzyme A synthase 1; IR, insulin resistance; Ivd2, Isovaleryl-CoA dehydrogenase; KIC, $\alpha$-ketoisocaproic acid; KLF15, Kruppel like factor-15; mTOR, mammalian target of rapamycin; Mut, methylmalonyl-Coenzyme A mutase; PDH, pyruvate dehydrogenase; PPM1K, mitochondrial-targeted protein phosphatase; Rer1, Retention in endoplasmic reticulum sorting receptor 1; Rpl41, Ribosomal protein L41; Rp1711, Ribosomal protein L7-like 1; T2D, type 2 diabetes
\end{abstract}




\begin{abstract}
Branched-chain $\alpha$-keto acids (BCKAs) are downstream catabolites of branched-chain amino acids (BCAAs). Mitochondrial oxidation of BCKAs is catalyzed by branched-chain ketoacid dehydrogenase (BCKDH), an enzyme sensitive to inhibitory phosphorylation by BCKD kinase (BCKDK). Emerging studies show that defective BCAA catabolism and elevated BCKAs levels correlate with glucose intolerance and cardiac dysfunction. However, if/how BCKDH and BCKDK exert control on the availability and flux of intramyocellular BCKAs and if BCKA reprograms nutrient metabolism by influencing insulin action remains unexplored. We observed altered BCAA catabolizing enzyme expression in the murine heart and skeletal muscle during physiological fasting and diet-induced obesity and after ex vivo exposure of $\mathrm{C} 2 \mathrm{C} 12$ cells to increasing concentration of saturated fatty acid, palmitate. BCKAs per se impaired insulin-induced AKT phosphorylation and AKT activity in skeletal myotubes and cardiomyocytes. In skeletal muscle cells, mTORC1 and protein translation signaling was enhanced by BCKA with concomitant suppression of mitochondrial respiration. Lowering intracellular BCKA levels by genetic and pharmacological activation of BCKDHA enhanced insulin signaling and activated pyruvate dehydrogenase, an effector of glucose oxidation and substrate metabolism. Our findings suggest that BCKAs profoundly influence muscle insulin function, providing new insight into the molecular nexus of BCAA metabolism and signaling with cellular insulin action and respiration.
\end{abstract}

\title{
Keywords
}

Insulin signaling, BCKA, BCKDH, skeletal muscle, cardiomyocytes, mTORC1 


\section{Introduction}

Branched-chain amino acids (BCAAs) and their catabolites are bioactive molecules with a broad repertoire of metabolic actions in cellular health and disease (1-6). Leucine, isoleucine and valine (BCAAs) are reversibly transaminated by branched-chain aminotransferase (BCAT) to yield branchedchain $\alpha$-keto acids (BCKA), specifically $\alpha$-ketoisocaproate or ketoleucine ( $\alpha$-KIC), $\alpha$-ketoisovalerate or ketovaline ( $\alpha$-KIV), and $\alpha$-kethomethylvalerate or ketoisoleucine ( $\alpha-\mathrm{KMV})$. BCKAs are irreversibly decarboxylated by BCKA dehydrogenase (BCKDH), a rate-limiting step in BCAA catabolism. BCKDH activity is tightly regulated by BCKA dehydrogenase kinase (BCKDK) mediated inhibitory phosphorylation (7-9) of BCKDH or BCKDH dephosphorylation and activation by protein phosphatase 2C $(\mathrm{PP} 2 \mathrm{Cm})(4,10)$. Transcriptional regulation of the BCAA catabolizing enzymes and BCAA catabolism is controlled by Kruppel like factor 15 (KLF15) (11), which also regulates glucose and fat oxidation (12-14). Emerging studies have shown that not only inborn mutations in BCAA enzymes, but also dysfunctional BCKA oxidation manifest in metabolic disorders like cancer $(15,16)$, obesity and insulin resistance (17-19) ischemia (20) and, diabetic cardiomyopathy $(21,22)$.

Skeletal and cardiac muscle insulin signaling and sensitivity are critical for metabolic homeostasis and organ function $(23,24)$. A strong association between plasma BCAAs, muscle BCAA catabolic gene expression and insulin resistance (IR) has been reported in several human and rodent models of obesity $(25,26)$. Whether defects in muscle BCAA catabolizing enzyme expression and activity precede or follow obesity-induced IR remains unclear. Strikingly, pharmacological inhibition of BCKDK in ob/ob and diet-induced obese (DIO) mice normalized BCAA catabolism and attenuated IR (26), signifying that restoring BCAA catabolism and clearing BCAA metabolites in endocrine disorders has beneficial functional outcomes. Plausibly a metabolic environment favouring the accumulation of BCAA catabolites reprograms substrate utilization and causes metabolic dysfunction. However, it remains unknown if BCKAs directly impact muscle insulin signaling to influence substrate utilization and mitochondrial function. A recent report demonstrated that incubation of cardiomyocytes with high 
levels of BCKAs reduces glucose uptake (27) and remodels mitochondrial respiration (28), questioning the effect of BCKA on insulin signaling and action.

In this study, we investigated if acute fasting and chronic diet-induced obesity alter the expression of BCAA catabolic enzymes, and if this effect is attributed to insulin action or lipid overload. We examined the influence of individual BCKAs on both cardiac and skeletal muscle insulin signaling and protein translation machinery including glucose and mitochondrial metabolism. Lastly, we examined whether targeting BCAA catabolizing enzymes was sufficient to alter intracellular BCKA levels to impact muscle insulin signaling. 


\section{Results}

\subsection{Overnight fasting augments $\mathrm{BCKDH}$ phosphorylation and protein expression in the cardiac tissue}

\section{but not in the gastrocnemius muscle}

We examined whether acutely limiting nutrient intake (fasting) alters transcriptional or posttranslational levels of BCAA catabolic enzymes in the cardiac and skeletal muscle (Fig 1a). Male C57BL/6 mice subjected to overnight fasting exhibited a decline in body weight, serum glucose and liver weight (Table S1) when compared to either ad libitum fed or refed mice. Ventricular weight to body weight ratio remained unchanged between groups (Table S1). mRNA expression of BCAA catabolic enzymes (Bckdha, Bckdk, Bcat2, Klf15, Oxct2a, Ivd2, Hmgcs 1 and Mut) was similar between fed, fasted and refed groups in gastrocnemius and cardiac muscle (Fig 1b-c). Inactivating phosphorylation of BCKDE1 $\alpha$ at Ser 293 (suggestive of decreased BCKDHA activity) and total protein content of BCKDHA and BCKDK were unaltered in the gastrocnemius muscle (Fig 1d). However, a marked increase in phosphorylation of BCKDE1 $\alpha$ at Ser 293 was observed in the fasted hearts, which returned to fed levels upon $4 \mathrm{~h}$ of refeeding (Fig 1e). Interestingly, BCKDHA protein levels were decreased upon fasting and were restored in the hearts of refed mice (Fig 1e). In the heart, BCKDK protein levels remained unaltered across all the groups (Fig 1e). Prior studies in the liver have demonstrated that BCKDHA phosphorylation is decreased following refeeding resulting in increased BCAA oxidation $(29,30)$ and inhibition of fatty acid oxidation and ketone body generation (31). During fasting, reduced insulin relieves inhibition of fatty acid oxidation in the heart. We propose that the inactivation of BCKDHA downregulates BCAA oxidation thereby rendering fatty acids as dominant substrates for oxidation during fasting. Indeed, leucine inhibited palmitate oxidation in aerobically (30 min) perfused mouse heart (Fig 1f). Since muscle BCAA catabolizing enzyme expression decreased in the presence of excess lipids (32) we postulate that BCAA and fatty acids are competing substrates in the heart likely regulating expression and activity of enzymes facilitating their respective catabolism by affecting insulin signaling. 


\subsection{Expression of BCAA catabolic enzymes is differentially regulated in the cardiac and skeletal muscles}

\section{following DIO}

We next ascertained if amino acid metabolizing enzymes in the muscle were temporally regulated in a model of progressive lipid excess and hyperinsulinemia (diet-induced obesity). Male C65/BL6 mice were fed a high-fat high sucrose (HFHS) diet and blood and tissues were collected at 2, 4, 8, and 13 weeks post feeding to determine the BCAA catabolic enzyme expression in the gastrocnemius muscle and heart (Fig 2a). To examine the effect of progressive lipid loading on BCAA metabolizing enzymes, we compared the expression profile of genes involved in BCAA catabolism in the gastrocnemius muscles between $2 \mathrm{wk}$ and 13 wk of HFHS feeding. mRNA expression of Mut and $I v d 2$, intermediary effector enzymes of the BCAA oxidation pathway, was reduced in the gastrocnemius muscle at 13 wk compared to 2 wk HFHS fed mice (Fig 2b), consistent with a prior report in mice fed a (60\%) high fat diet (HFD) (32). Interestingly, Hmgcs 1 levels were upregulated in the gastrocnemius muscle in $13 \mathrm{wk}$ fed mice compared to 2 wk fed mice (Fig 2b), possibly as a compensatory mechanism to maintain CoA pools. In the heart, mRNA expression of the BCAA catabolic enzymes, except for KLF15, remained unaltered in a setting of DIO (Fig 2c). Since the earliest changes in mRNA expression were not detected until $13 \mathrm{wk}$, we used $4 \mathrm{wk}$, and not $2 \mathrm{wk}$, HFHSfed mice as controls to analyze protein expression. Phosphorylation of BCKDE1 $\alpha$ at Ser 293 in the gastrocnemius muscles was unchanged at $8 \mathrm{wk}$ but increased at $13 \mathrm{wk}$ in HFHS-fed mice compared to the 4 wk HFHS-fed mice (Fig 2d). Unlike the fasted state (acute lipid turnover), no changes in BCKDH complex phosphorylation was found in hearts from HFHS fed mice (chronic lipid excess) compared to chow (Fig 2e). Together, these data demonstrate that unlike acute fasting, chronic HFHS feeding downregulates enzymes involved in BCAA catabolism in the gastrocnemius muscle but not the heart.

Chronic lipid overload not only drives IR but also increases systemic and myocellular BCAAs $(11,25)$ and BCKAs (11). To simulate the gradual increase in fatty acids observed in obesity and IR ex vivo, C2C12 cells were treated with low $(0.2 \mathrm{mM})$ and high $(0.4 \mathrm{mM})$ palmitate for $16 \mathrm{~h}$. A marked downregulation of Ivd2 mRNA levels with concomitant upregulation of Hmgcs1 was observed in C2C12 cells (Fig S1a) consistent with the DIO data (Fig 2b). Since lipid overload altered the expression of distinct BCAA 
catabolic enzymes, at least in the skeletal muscle, we raised the question if catabolic intermediates of BCAA metabolism, such as BCKAs, influence muscle insulin signaling. Furthermore, we observed a trend towards increased total fasted serum BCKAs as early as $13 \mathrm{wk}$ of HFHS diet feeding (Fig 2f), suggesting that impaired BCAA catabolism in obesity not only elevates levels of BCAAs but also augments BCKAs $(17,33)$.

\subsection{BCKA inhibit insulin signalling in skeletal and cardiac muscle cells}

BCKAs are BCAA metabolites that are now emerging as clinically relevant biomarkers for IR $(34,35)$. BCKA are not only generated intracellularly but also transported between tissues to support nitrogen balance, ketone body metabolism, and gluconeogenesis (36,37). Short term (30 min) treatment of C2C12 cells with increasing concentrations (1 mM, $2 \mathrm{mM}$ and $5 \mathrm{mM})$ of 4-methyl 2-oxopentanoic acid sodium salt (ketoleucine) resulted in a concentration-dependent impairment of insulin-induced AKT isoform 1 phosphorylation at Ser 473 (Fig S2a). Notably, insulin-mediated activating phosphorylation of insulin receptor substrate 1 (IRS 1) at Tyr 612 was inhibited by ketoleucine at a concentration of $5 \mathrm{mM}$ but not 1 or $2 \mathrm{mM}$ (Fig S2a). Ketoleucine mediated inhibition of AKT1 and IRS1 phosphorylation was observed at $15 \mathrm{~min}$ and persisted until $30 \mathrm{~min}$ of ketoleucine treatment (Fig S2b). However, phosphorylated AKT1 levels were restored to control levels at $60 \mathrm{~min}$ (Fig S2b). The inhibitory effect of ketoleucine on insulinstimulated AKT1 phosphorylation in $\mathrm{C} 2 \mathrm{C} 12$ cells was also recapitulated in the rat L6 muscle cell line (Fig S2c). We next tested if BCKAs modulated palmitate-induced IR. In C2C12 (Fig 3a) and L6 cells (Fig S2d) incubated with $0.4 \mathrm{mM}$ palmitate, ketoleucine did not exacerbate palmitate mediated decreases in AKT1 Ser 473 phosphorylation and phosphorylation of IRS1 at Tyr 612 (Fig 3a). To address whether other ketoacids also impact skeletal muscle insulin signalling, we treated $\mathrm{C} 2 \mathrm{C} 12$ cells with $5 \mathrm{mM}$ sodium-3methyl-2-oxobutyrate (ketovaline) (Fig 3b), 5 mM 3-methyl-2-oxovaleric acid sodium salt (ketoisoleucine) (Fig 3c) and a combination of all BCKA (Fig S2e) in the presence or absence of $0.4 \mathrm{mM}$ palmitate. Similar to the effect of ketoleucine, AKT1 Ser 473 phosphorylation was impaired by both ketovaline and ketoisoleucine in the absence of palmitate (Fig 3b-c). Ketovaline, but not ketoleucine or ketoisoleucine, 
reduced AKT1 phosphorylation at Thr 308 (Fig 3b). Ketoacids, in combination, significantly reduced AKT1 phosphorylation at Ser 473 in C2C12 cells (Fig S2e). Our data are consistent with a recent report which demonstrated that BCKAs inhibited insulin signalling in 3T3-L1 adipocytes (26). Consistent with reduced AKT1 phosphorylation, insulin induced AKT1 activity was also decreased by ketoleucine and ketovaline (Fig 3d). Ketoisoleucine did not influence AKT1 activity, perhaps reflecting its more modest ability to inhibit insulin-stimulated AKT1 phosphorylation (Fig 3d). Ketoleucine inhibited insulin-mediated AKT1 Ser 473 phosphorylation in the absence of palmitate not only in muscle cells but also in neonatal rat cardiomyocytes (NRCMs) (Fig 4a-b) and adult rat cardiomyocytes (ARCMs) (Fig 4a \& c). Similarly, treatment with ketovaline and ketoisoleucine also decreased insulin-stimulated AKT1 S473 phosphorylation in ARCMs (Fig S3a). Taken together, these data suggest that BCKAs per se is equivalent to palmitate in inhibiting insulin signalling in skeletal and cardiac muscle cells.

\subsection{Ketoleucine blunts insulin-induced decreases in PP2A activity}

Since acute BCKAs treatment impaired insulin signaling, we questioned whether BCKA target upstream modulators of AKT phosphorylation. Protein phosphatase 2A (PP2A) dephosphorylates and inactivates AKT (38), whereas insulin inhibits PP2A activity $(39,40)$, preventing AKT dephosphorylation and increasing AKT activity $(40,41)$. We examined if ketoleucine alters PP2A activity to modulate insulin signaling (Fig 5a). The presence of ketoleucine prevented the inhibitory effect of insulin on PP2A activity, while pre-treatment with the PP2A inhibitor, okadaic acid (OA), decreased ketoleucine's effect (Fig 5b). We next examined if changes in PP2A activity corresponded with AKT phosphorylation. Since ketoleucine did not affect AKT Thr 308 phosphorylation, we chose to examine AKT 2 phosphorylation, an additional readout of insulin signaling. OA increased phosphorylation of both AKT isoforms, with a more significant effect observed for AKT1 Ser 473 (Fig 5c). Ketoleucine exhibited a more significant inhibitory effect on AKT2 Ser 474 than AKT Ser 473 phosphorylation (Fig 5c). Pre-treatment with OA partially rescued AKT1 Ser 473 phosphorylation and significantly increased AKT2 Ser 474 phosphorylation (Fig 5c). Interestingly, pre-treatment of cells with ketoleucine followed by OA and insulin treatment augmented AKT 
phosphorylation more than OA alone (data not shown). These data show that ketoleucine blunts insulininduced inactivation of PP2A activity.

\subsection{Affecting clearance of BCKAs by genetic and pharmacological modulation of BCAA catabolizing enzymes influences muscle insulin signalling}

We next examined if BCKAs mediated impairment in insulin signaling can be precipitated by increasing endogenous BCKA accumulation as opposed to exposure to exogenous BCKAs. Enzymatic activity of BCKDH determines the catabolic fate of BCKAs (25). BCKDH activity is inhibited by BCKDKmediated phosphorylation, an effect that is reversed by PPM1K-mediated BCKDH dephosphorylation (Fig 6a). We hypothesized that targeting BCAA catabolizing enzymes will facilitate oxidation and clearance of intracellular BCKAs, rescuing impaired insulin signaling induced by BCKAs. C2C12 myotubes were transduced with adenoviruses overexpressing BCKDK and BCKDHA, the key subunit of BCKDH complex (Fig 6b). Intracellular BCKAs were significantly increased in BCKDK overexpressing cells and decreased in BCKDHA overexpressing cells (Fig 6b), signifying that altering BCAA metabolic enzyme levels changes cellular BCKA content. We next examined if this change in intracellular BCKA levels precipitates alterations in insulin signaling. Consistent with increased accumulation of intracellular BCKAs, BCKDK overexpression decreased insulin-mediated phosphorylation of AKT isoform 1 at Ser 473 and AKT isoform 2 at Ser 474 but not at Thr 308 residue of AKT1 (Fig 6c). AKT1 phosphorylation at both Ser 473 and Thr 308 as well as at the Ser 474 residue of AKT2, were increased in myotubes overexpressing BCKDHA in the presence of insulin (Fig 6d). We observed that BCKDHA was robustly expressed in myoblasts and was undetected by day 4 of differentiation (data not shown). Silencing BCKDHA in C2C12 myoblasts impaired AKT1 Ser 473 phosphorylation, as shown by immunoblot (Fig 6e) and ELISA analysis (Fig S4a). Interestingly, BCKDHA depletion induced a more significant decrease in AKT2 Ser 474 phosphorylation when compared to AKT1 Ser 473 (Fig 6e). Improved insulin signaling induced by BCKDHA overexpression resulted in increased pyruvate dehydrogenase (PDH) activity (Fig S4b). However, BCKDHA silencing did not impact PDH activity (Fig S4b). Similar effects on AKT1 Ser 473 
phosphorylation were observed in NRCMs with either overexpression or knockdown of BCKDHA (Fig S4c).

In addition to genetic manipulation of BCAA catabolizing enzymes, we also employed pharmacological inhibition of BCKDK as an alternative approach to modulate intracellular BCKA levels. 3,6-dichlorobenzothiophene-2-carboxylic acid (BT2) is a selective inhibitor of BCKDK (Fig 7a) which increases BCKDH activity $(22,26)$ by inhibiting $\mathrm{BCKDH}$ phosphorylation. A 20-h exposure of C2C12 myotubes to BT2 reduced intracellular BCKAs (Fig 7b), signifying increased BCKDH activity, consistent with previous reports $(22,26)$. Furthermore, BT2 markedly increased Klf15 and moderately increased Bcat2 mRNA levels (Fig 7c), indicating increased BCKAs flux towards oxidation. BT2 also decreased BCKDE1 $\alpha$ Ser 293 inactivating phosphorylation in a concentration-dependent manner (Fig 7d). Further, BT2 increased insulin mediated AKT phosphorylation in $\mathrm{C} 2 \mathrm{C} 12$ cells, as shown by immunoblot (Fig 7e) and ELISA analysis (Fig S5a). Similar insulin-dependent effects of BT2 on AKT1 phosphorylation were also observed in NRCMs (Fig S5b). We next questioned whether BT2 could rescue insulin signaling impairment in BCKDHA depleted cells. BT2 restored AKT1 Ser 473 but not AKT2 Ser 474 phosphorylation in BCKDHA silenced C2C12 cells (Fig 7f). BT2 treated C2C12 myotubes displayed increased Glut1 but not Glut 4 mRNA levels (Fig 7g). Additionally, BT2 tended to increase insulin-induced pyruvate dehydrogenase (PDH) activity compared to vehicle-treated cells (Fig 7h), supporting the view that BT2 activates PDH to augment muscle glucose oxidation in response to enhanced insulin signaling (42-44). A functional insulin signaling pathway not only signifies a better coupling of glycolysis and glucose oxidation but is an index of efficient lipid oxidation. Indeed, insulin resistance in HFD fed mice is often associated with incomplete fat oxidation and metabolic inflexibility in the skeletal muscle $(45,46)$. C2C12 cells treated with BT2 displayed increased ${ }^{14} \mathrm{C}$ palmitate oxidation (Fig 7i) and a trend towards the reduced accumulation of acidsoluble metabolites (Fig 7j), suggesting that the favourable response of BT2 on insulin signaling is related to BCKA clearance and its downstream effects on lipid oxidation. Our findings are in agreement with a prior study where the key enzyme of fatty acid biosynthesis, ATP citrate lyase, was reported to be 
inactivated by BT2 (47). Together, these results suggest an intricate integration of BCKAs and lipid metabolism that could be a plausible driver for muscle IR.

\subsection{BCKAs upregulate mTORC1 and protein translation signaling in skeletal muscle cells}

BCAAs and BCKAs augment mTOR signaling (48-51) in different cell types $(52,53)$. We examined if the effect of BCKAs on inhibiting the insulin signaling pathway was associated with increased mTOR signaling (Fig 8a), which is known to negatively regulate insulin signaling (54). Phosphorylation of mTORC1 at Ser 2448 and its downstream target P70S6K at Thr 389 was significantly increased by ketoleucine and ketoisoleucine but not ketovaline (Fig 8b). Next, we assessed the effect of individual BCKAs on other downstream targets of mTOR involved in protein translation. Eukaryotic elongation factor 2 (eEF2) mediates ribosomal translocation during the elongation phase of mRNA translation. Phosphorylation of eEF2 at Thr 56 mediated by eEF2 kinase (eEF2K) interferes with its binding to the ribosome and inhibits translation elongation. Increased mTORC1 signaling inhibits eEF2K and promotes dephosphorylation and activation of eEF2 (55). Consistent with mTORC1 activation, ketoleucine and ketoisoleucine, but not ketovaline, downregulated eEF2 phosphorylation at Thr 56 (Fig 8b). Translation initiation is regulated by mTOR dependent phosphorylation and activation of eukaryotic initiation factor 4G (eIF4G), at Ser 1108 (56). We observed increased eIF4G Ser 1108 phosphorylation in C2C12 cells treated with ketoleucine and ketoisoleucine, but not ketovaline (Fig 8b). Together, our findings are in agreement with a recent study in adipocytes (26) and show that acute incubation with BCKAs, particularly ketoleucine and ketoisoleucine, upregulates $\mathrm{mTORC} 1$ activity and protein translation signaling. Consistent with this notion, BCKDHA silencing in $\mathrm{C} 2 \mathrm{C} 12$ cells increased phosphorylated mTOR, P70S6K as well as eIF4G (Fig 8c) with concomitant inhibition of insulin signaling (Fig. 6e).

Changes in mitochondrial function alter protein translation. As reported in prior studies, ROS overproduction attenuates translation elongation and pauses translation $(57,58)$. Directing TCA cycle intermediates away from ETC towards translation and lipid and nucleotide biosynthesis suppress mitochondrial respiration. Since mTOR regulates mitochondrial oxygen consumption and oxidative 
capacity (59), we questioned if BCKAs induced mTORC1 activation in $\mathrm{C} 2 \mathrm{C} 12$ cells impacts oxidative and glycolytic metabolism and mitochondrial respiration. Ketoleucine and ketoisoleucine suppressed maximal oxygen consumption rate with no changes in basal respiration (Fig S6a). ATP production was significantly reduced by ketoleucine but remained altered by ketoisoleucine or ketovaline (Fig S6b). Spare respiratory capacity was unchanged following incubation with individual BCKAs (Fig S6c). Our findings are consistent with prior studies demonstrating that BCKAs suppress respiration in cardiac mitochondria (11). Since mitochondrial oxygen consumption and ATP production were altered, we next examined whether ketoleucine treatment influences mitochondrial fatty acid oxidation. Although acute treatment with ketoleucine did not alter ${ }^{14} \mathrm{C}$ palmitate oxidation (Fig S6d), $\mathrm{CO}_{2}$ derived from the acid-soluble metabolite fraction (incomplete fatty acid oxidation) was increased in cells incubated with ketoleucine (Fig S6e). Together, our findings suggest that BCKA mediated impairment in insulin signaling is associated with increased mTOR signaling and suppressed mitochondrial respiration and fat oxidation. 


\section{Discussion}

Prior studies have either supported $(17,25,60,61)$ or challenged $(25,62-64)$ the paradigm that increased circulating BCAAs is a hallmark of IR, T2D and obesity by utilizing genetic $(25,26,65)$ and dietinduced rodent models of obesity and IR. The inconsistencies across different studies relating circulating BCAAs levels to murine obesity and IR and its effects on metabolism are partly attributed to differential dietary intake, tissue uptake, and nutritional status. Coordinate and inter tissue regulation of BCAA metabolizing enzymes also contribute to the reported inconsistencies since there are contradictory findings on the impact of IR on BCAA catabolic enzyme expression in the skeletal muscle $(26,32,66)$. Remarkably, elevations in circulating BCKAs correlated better with the severity of IR and T2D pathogenesis $(34,35)$. Elevated BCKA is an outcome of impaired action of BCAA catabolizing enzymes, BCKDHA $(67,68)$, PPM1K (69-71) and KLF15, the transcriptional activator of BCAA metabolism $(11,25)$. BCKA is generated not only systemically but also intracellularly in tissue capable of BCAA intake and/or BCAA oxidation. A significant amount of BCKA is generated within the skeletal muscle for transport to other organs, like the liver and kidney (72). Moreover, since skeletal muscle is the major organ of insulin-induced glucose disposal (24), it is plausible that loss of BCAA catabolizing enzyme function can overwhelm skeletal muscle BCKA concentration and perturb downstream metabolism. We hypothesized whether increasing BCKAs or targeting BCAA catabolic enzymes exert effects on insulin signaling and function to govern myocyte metabolism.

In this study, we demonstrated tissue specific mRNA and post-translational changes in BCAA catabolizing enzyme in mice subjected to acute (physiological fasting), and chronic (DIO) nutritional stress, an effect that is likely attributed to altered insulin action or lipid content. Exposure to a lipotoxic milieu suppressed BCAA catabolic enzyme expression both in vivo and in vitro indicating that that fatty acidinduced defects in BCAA catabolism (either BCAA metabolic enzyme inhibition or accumulation of downstream BCAA metabolites) disrupting insulin function. Further, we report that acute exposure of supraphysiological concentrations of individual BCKAs was sufficient to induce insulin signaling impairment in both cardiac and skeletal muscle cells. Inhibiting PP2A, a phosphatase that dephosphorylates 
AKT, reversed BCKAs effect on insulin signaling. We also demonstrate that reducing intracellular BCKAs by genetic or pharmacological modulation of $\mathrm{BCKDH}$, sensitized cardiac and skeletal muscle cells to insulin. Alternatively, we observed that augmenting intracellular BCKAs by adenoviral silencing of BCKDH or exogenous application of BCKAs in the skeletal muscle cells resulted in increased mTORC1 signaling, a negative regulator of insulin action.

Intracellular BCAAs catabolism is an essential determinant of circulating and intracellular BCKAs levels. Indeed BCAAs catabolic enzymes, BCATm, PPM1K and BCKDHA are downregulated in adipose tissues (70,73-75) of rodents with obesity and IR. In our model of DIO, we observed a significant decrease in downstream genes of BCAAs catabolism, namely, Ivd2 and Mut mRNA levels in the gastrocnemius muscle at 13 wk post-HFHS diet feeding. Similar effects on BCAA catabolic enzyme mRNA expression were made in $\mathrm{C} 2 \mathrm{C} 12$ myotubes exposed to incremental concentrations of palmitate. Intriguingly in both the in vivo and in vitro model of lipid overload, we found a compensatory increase in Hmgcs1 mRNA levels, likely a mechanism to replenish acetyl CoA pools. Our findings are in agreement with a prior study demonstrating decreased expression of BCAAs oxidative genes in human and rodent muscles with IR (32). Moreover, we found an increase in inhibitory phosphorylated BCKDH Ser 293 levels in the gastrocnemius muscle fed HFHS diet for 13 wk likely signifying inhibited BCKDH activity and thereby BCAAs catabolism. Our data are supported by studies in rodent models of obesity demonstrating loss of BCKDH activity and BCAA oxidation in multiple tissues, like adipose, liver and heart $(67,68)$. In contrast, several groups have also reported that skeletal muscle BCAA catabolic genes are unaltered in diet-induced obese mice (21), ob/ob mice (26) or in IR women with normoglycemia (66). Furthermore, a prior study reported no significant differences in the inhibitory phosphorylation of BCKDHA in the gastrocnemius muscles of mice fed $60 \%$ HFD for 10 weeks (21). We attribute this inconsistency to the difference in diet composition and the duration post-feeding and also the nutritional state of the animal before euthanasia. Importantly, our study, for the first time, reports the temporal effect of HFHS feeding on BCAA catabolic enzymes in skeletal and cardiac muscle. Together, our data are consistent with previous reports linking lipid metabolism to remodeling of muscle BCAA catabolism $(2,32,76)$. Strikingly, in our study, acute 
modulation of nutritional status had a profound and distinct impact on post-translational modification of BCAA metabolizing enzymes in the heart but not skeletal muscle, whereas, chronically, in a setting of DIO, BCAA metabolizing enzymes were altered in the skeletal muscle but not the heart.

We and others have demonstrated that despite unchanged plasma BCAAs, systemic and tissue-specific BCKAs were elevated in obese animals (26) as well as in patients with obesity undergoing cardiac surgery (unpublished data). In our study, we observed marginal increases in circulating BCKAs at 13 wk following HFHS feeding. Emerging studies have shown that BCKAs alter carbohydrate metabolism in multiple insulin-responsive tissues (77),(78). BCKAs inhibit glucose uptake in cardiomyocytes (27) and skeletal muscle (79) and reducing BCKAs levels by cardiac-specific BCATm deletion has been attributed to improvement in basal and insulin-induced glucose oxidation along with increased ATP production (78). Moreover, in the liver and cultured hepatic cells, BCKAs has been demonstrated to upregulate the glycogenolytic enzyme, glycogen phosphorylase (77). However, it was unclear if BCKAs' effects on metabolism involved changes in insulin signaling. Moreover, a recent study demonstrated that BCAA restriction did not affect cardiac insulin signaling in Zucker fatty rats (80) indicating that downstream metabolites of BCAAs, such as BCKAs, are more potent mediators of insulin signaling. Interestingly despite elevated levels of BCAAs, BCAT2 KO mouse unexpectedly develops resistance to diet-induced obesity and presented with increased glucose disposal, improved glucose tolerance and enhanced insulin sensitivity (81) likely attributed to reduced BCKA levels. We demonstrated that supraphysiological levels of exogenously supplied BCKAs impaired insulin signaling in the skeletal and cardiac muscle cells. Moreover, BCKAs mediated impairment of insulin induced AKT phosphorylation was reversed by okadaic acid, a bonafide inhibitor of PP2A phosphatase that inhibits AKT phosphorylation. Our data are consistent with a recent study in cultured 3T3-L1 adipocytes depicting that BCKAs directly impaired insulin signaling (26).

Prior studies have examined the direct effects of BCAA and BCKA but not a consequence of disrupted BCAA catabolic enzyme expression on cellular metabolism and insulin function. This study, for the first time, demonstrates that altering intracellular BCKAs levels by overexpressing or silencing 
BCKDHA or BCKDK impacts insulin signaling both in the skeletal and cardiac muscle cells. Overexpressing BCKDHA marginally decreased intracellular BCKAs levels which were sufficient to reverse the inhibition of AKT phosphorylation by direct incubation with BCKAs. Conversely, adenoviral silencing of BCKDHA or overexpressing BCKDK, the kinase inactivating BCKDHA, impaired AKT phosphorylation. Our finding supports the correlation between intracellular BCKAs levels and insulin mediated AKT phosphorylation in the $\mathrm{C} 2 \mathrm{C} 12$ myotubes. Similar effects on insulin-mediated AKT phosphorylation was observed in the muscle by incubating with BCKDK inhibitor, BT2 which increased intracellular BCKAs clearance. Our ex vivo findings are consistent with the in vivo study wherein BT2 treatment in ob/ob mice improved insulin-induced AKT phosphorylation in the skeletal muscle but not in the liver or white adipose tissue (26). Interestingly, changes in BCKDHA content profoundly affected AKT2 Ser 474 phosphorylation than on AKT1 Ser 473. Previous studies have reported the importance of AKT2 Ser 474 phosphorylation for maximal activation of AKT and insulin-regulated processes (82). Strikingly, BT2 treatment in $\mathrm{C} 2 \mathrm{C} 12$ cells with BCKDHA silencing rescued insulin induced AKT phosphorylation on Ser473 but not Ser 474. It is plausible that distinct subunits of BCKDHA exhibit effects on regulating specific AKT isoforms. Nevertheless, our data indicate that lowering intracellular BCKAs levels augment insulin signaling in the muscle. Upon a reduction in intracellular BCKAs levels by either BT2 treatment or BCKDHA overexpression sensitized insulin action as reflected by increased PDH activity. Indeed, hearts with PPM1K deletion (20) and plasmodium with loss of BCKDH function (83) exhibited reduced PDH activity leading to impaired glucose oxidation (84). In our study, increased PDH activity in BT2 treated $\mathrm{C} 2 \mathrm{C} 12$ cells corresponded with the upregulation of Glut1 mRNA expression. BCKAs levels are downregulated in Glut1 overexpressing cardiomyocytes (85) suggesting that BCKA generation and utilization are intricately coupled to glucose metabolism via its effects on insulin signaling.

Muscle insulin signaling is inhibited by mTOR, P70S6K and ribosomal S6, proteins activated by BCAAs (86). A key function of nutrient sensor mTOR is to maintain the available amino acid pool by regulating protein translation. Indeed during DIO, glucolipotoxicity exacerbates IR with concomitant mTOR activation in the heart and skeletal muscle $(87,88)$. We demonstrate that the three BCKAs 
individually activated mTOR, with ketoleucine and ketoisoleucine exhibiting pronounced effects which are in agreement with prior studies in cultured adipocytes (26) showing increased mTORC1 activity and defective insulin pathway in response to BCKA exposure (89). mTOR activation increases protein translation and synthesis (90). A concerted action of eukaryotic elongation factor 2 (eEF2), eEF2 kinase (eEF2K) and eukaryotic initiation factor $4 \mathrm{G}(\mathrm{eIF} 4 \mathrm{G})$ in conjunction with mTORC1 activation governs translation signaling $(55,56)$. Depleting C2C12 cells of BCKDHA or treating with BCKAs upregulated eIF4G phosphorylation at Ser 1108, increased phosphorylated mTOR, P70S6K and decreased eEF2 Thr 56 phosphorylation, events which promote translation. We theorize that intracellular BCKAs is an anabolic sensor facilitating mTOR activation and also acting as an endogenous inhibitor of insulin signaling. Interestingly, cardiomyocytes incubated with BCKAs acutely downregulated AKT signaling triggering cell death (91), suggesting that excessive mitogenic signaling including translation, can be an energetically expensive process compromising cellular survival. Supporting this paradigm we and others demonstrate that BCKAs suppress mitochondrial oxygen consumption in $\mathrm{C} 2 \mathrm{C} 12$, cardiac (11), neuronal (37) and hepatic cells (77). BCKAs also increased the accumulation of acid soluble metabolites, a signature of incomplete fatty acid oxidation in $\mathrm{C} 2 \mathrm{C} 12$ cells.

Taken together, we report that muscle BCAA catabolizing enzymes expression is modulated by acute and chronic changes in insulin during physiological fasting and diet-induced obesity, as well as exposure to increasing concentration of fatty acids. In an environment of chronic lipid overload downregulation of BCAA catabolic enzyme expression accumulates BCKAs causing IR. Cardiac and skeletal muscle cells depleted of BCKDHA and treatment with exogenous BCKAs displayed defective insulin signaling with concomitant activation of $\mathrm{mTORC} 1$ and protein translation. BCKAs induced incomplete oxidation of fatty acids and suppressed mitochondrial respiration. Additional studies are warranted to clarify if the metabolic effects of BCKA are a cause or effect of changes in insulin signaling or mitochondria function or protein translation. Moreover, augmenting BCKAs clearance by overexpressing BCKDHA or pharmacological targeting of BCKDK enhanced insulin signaling and glucose utilization. Our findings indicate that BCKAs can independently impair insulin signaling by modulating upstream effectors of AKT (Fig 8d). This study 
bioRxiv preprint doi: https://doi.org/10.1101/2020.02.21.960153; this version posted February 22, 2020. The copyright holder for this preprint

(which was not certified by peer review) is the author/funder, who has granted bioRxiv a license to display the preprint in perpetuity. It is made available under aCC-BY-NC-ND 4.0 International license.

advances the knowledge on the molecular nexus of BCAA metabolism and signaling with cellular insulin action and respiration. 


\section{Materials and methods}

\subsection{Cell lines and culture conditions}

C2C12 cells were cultured in DMEM with 10\% fetal bovine serum (FBS, Thermo Fisher Scientific). Differentiation was induced with $0.2 \%$ fetal bovine serum for 4 to $6 \mathrm{~d}$ after cells reached $80 \%$ confluence. L6 cells were grown and maintained in $\alpha$ - minimal essential medium ( $\alpha$-MEM; Corning) containing 10\% FBS. Differentiation was induced with $2 \%$ FBS for 4 to 6 d. Cells were grown to $70-80 \%$ confluence. All the cell lines were maintained at $37^{\circ} \mathrm{C}$ in a humidified atmosphere of $5 \% \mathrm{CO}_{2}$.

\section{Primary cardiomyocyte culture}

Neonatal rat ventricular cardiomyocytes (NRCMs) were isolated from $2 \mathrm{~d}$ old Sprague-Dawley rat pups as described previously (88). Briefly, hearts were excised and the ventricles were minced into small pieces and digested in several steps using collagenase-type $2(2 \% \mathrm{~W} / \mathrm{V}$; Worthington Biochemical Corporation), DNase $(0.5 \% \mathrm{~W} / \mathrm{V}$; Worthington Biochemical Corporation) and trypsin $(2 \% \mathrm{~W} / \mathrm{V}$; Worthington Biochemical Corporation) with gentle stirring to dissociate heart pieces into single cells. Following digestion, non-muscle cells and fibroblasts were eliminated using differential plating of the cell suspension for $2 \mathrm{~h}$. Supernatant from differential plating, containing cardiomyocytes was collected and suspended in DMEM/F12 HAM (Sigma) growth medium [containing 10\% FBS, $10 \mu$ mol cytosine- $\beta$-Darabinofuranoside (ARAC; Sigma), Insulin-Transferrin-Selenium (ITS; Corning), 1X antimycotic/antibiotic solution (Sigma)] and plated in primaria cell culture plates (Corning). The following day, cells were washed and cultured in serum-free DMEM no glucose medium (GIBCO) [containing 10 $\mu$ mol ARAC, $0.05 \mathrm{mg}-1$ gentamycin, $1 \%$ penicillin-streptomycin and $10 \mathrm{mM}$ glucose] for $24 \mathrm{~h}$.

Adult rat cardiomyocytes (ARCMs) were isolated from adult male Sprague-Dawley rat hearts as described previously (88). Briefly, Langendorff method was used for retrograde perfusion of the isolated heart with Tyrode buffer [containing $1.49 \mathrm{mM} \mathrm{KCl}, 0.33 \mathrm{mM} \mathrm{KH}_{2} \mathrm{PO}_{4}, 11.69 \mathrm{mM} \mathrm{NaCl}, 12.51 \mathrm{mM}$ taurine, 1.206 $\mathrm{mM} \mathrm{MgSO}_{4}, 4.766 \mathrm{mM}$ HEPES, $3.604 \mathrm{mM}$ dextrose, and $\left.0.396 \mathrm{mM} \mathrm{L-carnitine} \mathrm{at} \mathrm{pH} 7.4\right]$ in $5 \% \mathrm{CO}_{2}-$ $95 \% \mathrm{O}_{2}$ at $37^{\circ} \mathrm{C}$. Following perfusion, the heart was digested with collagenase $(60 \mathrm{mg}$ collagenase, $25 \mu \mathrm{M}$ 
$\mathrm{CaCl}_{2}$ in $75 \mathrm{ml}$ Tyrode buffer) for $30 \mathrm{~min}$ in a recirculating mode. The digested heart was excised, and the ventricular pieces finely minced into a homogenous solution. Incremental physiological concentrations of calcium $(200 \mu \mathrm{M}, 500 \mu \mathrm{M}$ and $1 \mathrm{mM})$ was used to make the ventricular myocytes calcium tolerant, in the presence of $5 \% \mathrm{CO}_{2}-95 \% \mathrm{O}_{2}$. Dead cells were separated from the viable cardiomyocytes by gravity settlement. Cell pellet containing viable cardiomyocytes were resuspended in plating media [containing media 199 (Sigma), $26.2 \mathrm{mM}$ NaHCO3, $25 \mathrm{mM}$ HEPES, $1.24 \mathrm{mM}$ L-carnitine, $137 \mu \mathrm{M}$ streptomycin (Sigma), 280.6 $\mu \mathrm{M}$ penicillin (Sigma), $10 \mathrm{mM}$ taurine (Sigma) and 1\% BSA Fraction V ( Roche) at pH 7.4] and seeded at a density of 50-75 $\times 10^{3}$ cells/plate on laminin (Roche) coated plates. Plating media was replaced with fresh media after $4 \mathrm{~h}$ and cells were treated accordingly.

C2C12 and L6 cells were incubated with serum-free DMEM low glucose, leucine free media (Sigma); NRCMs with serum-free DMEM no glucose media and ARCMs with serum-free media 199 for $16 \mathrm{~h}$ before treating with 4-methyl 2-oxopentanoic acid sodium salt (ketoleucine, Sigma), sodium-3-methyl-2oxobutyrate (ketovaline, Sigma), 3-methyl-2-oxovaleric acid sodium salt (ketoisoleucine, Sigma) or a combination of all three (BCKAs). All the experiments were conducted with $5 \mathrm{mM}$ BCKAs (either individual or a mixture) for 30 mins unless mentioned otherwise. Insulin resistance was induced in $\mathrm{C} 2 \mathrm{C} 12$, L6 cells and cardiomyocytes by incubating them in their respective media containing $2 \%(\mathrm{w} / \mathrm{v})$ fatty acidfree bovine serum albumin (FAF-BSA; Roche) and $0.4 \mathrm{mM}$ sodium palmitate (Sigma) for 16h. Myotubes were incubated with $2 \%$ FAF-BSA in the absence of palmitate to mimic an insulin-sensitive state. To examine insulin signaling, cells were incubated with $100 \mathrm{nM}$ insulin (C2C12, L6, ARCMs) or $200 \mathrm{nM}$ insulin (NRCMs) or phosphate-buffered saline (PBS) for $15 \mathrm{~min}(\mathrm{C} 2 \mathrm{C} 12$, L6) or $20 \mathrm{~min}$ (NRCMs, $\mathrm{ARCMs}$ ). For the BT2 experiments, $\mathrm{C} 2 \mathrm{C} 12$ and $\mathrm{NRCMs}$ were pre-treated for $20 \mathrm{~h}$ with the desired concentration of BT2 (Sigma and Matrix Scientific). Cells were washed once and harvested in ice-cold PBS, followed by centrifugation at $18,000 \times \mathrm{g}$ for $10 \mathrm{~min}$ at $4^{\circ} \mathrm{C}$. Cell pellets were snap-frozen in liquid nitrogen and stored at $-80^{\circ} \mathrm{C}$ until further use. 


\subsection{Fat oxidation}

C2C12 myotubes were incubated with either $5 \mathrm{mM}$ ketoleucine for $30 \mathrm{mins}$ or $500 \mu \mathrm{M}$ of BT2 for $20 \mathrm{~h}$. Following the treatment, FAO was performed according to a prior study (92). Briefly, serum-starved cells were incubated with $1 \mu \mathrm{Ci}$ of ${ }^{14} \mathrm{C}$ palmitate (Perkin Elmer) at $37^{\circ} \mathrm{C}$ for $2 \mathrm{~h}$. Following the incubation, $70 \%$ perchloric acid was added to each well and the $\mathrm{CO}_{2}$ released was trapped in Whatman paper soaked with $3 \mathrm{~N} \mathrm{NaOH}$ for $1 \mathrm{~h}$. Incomplete fat oxidation was measured by the ${ }^{14} \mathrm{C}$ labeling of acid soluble metabolites in the supernatant collected after centrifugation of the media at $500 \mathrm{~g}$ for $10 \mathrm{mins}$ at $\mathrm{RT} .{ }^{14} \mathrm{C}$ levels were determined using a $\beta$-counter (Perkin Elmer). The assay was normalized by protein content.

\section{Isolated heart perfusion/Fat oxidation}

Hearts were perfused aerobically in working mode with Krebs-Henseleit buffer containing $1.2 \mathrm{mmol} /$ litre palmitate prebound to $3 \%$ delipidated bovine serum albumin, and $5 \mathrm{mmol} /$ litre glucose, as described previously (21). Mice were euthanized in the fed state, and hearts were dissected and subsequently perfused. Preload and afterload pressure were set to 11.5 and $50 \mathrm{~mm} \mathrm{Hg}$, respectively, unless otherwise stated. For measurement of fatty acid oxidation rates, hearts were perfused for $30 \mathrm{~min}$ with buffer containing 1.2 $\mathrm{mmol} /$ litre $\left[9,10-{ }^{3} \mathrm{H}\right]$ palmitate in the presence or absence of $5 \mathrm{mM}$ leucine. Following perfusion, atria were removed, and ventricles were snap-frozen in liquid nitrogen and stored at $-80^{\circ} \mathrm{C}$ until further processing.

\subsection{Animal Studies}

C57BL6J mice were procured from Jackson Laboratory (Bar Harbor, ME, USA). 10 wk old male C57BL/6J mice were divided into 3 groups and either fed ad libitum or fasted for $16 \mathrm{~h}$ or refed for $4 \mathrm{~h}$ following fasting ( $n=5$ each group). Body weight and blood glucose were measured before euthanasia and liver and ventricle weight was measured after dissection. Gastrocnemius muscles and heart tissue were snap-frozen in liquid nitrogen and stored at $-80^{\circ} \mathrm{C}$ until further processing.

8 wk old C57BL6J male mice were fed either chow or high-fat high sucrose (HFHS) diet and euthanized following overnight fast at 2, 4, 8 and $13 \mathrm{wk}$ ( $\mathrm{n}=5$ each group). Diet composition details are included in 
Table S2. Serum was collected after centrifuging the blood at $5000 \mathrm{rpm}$ for 5 mins. Gastrocnemius muscle and heart tissue were snap-frozen in liquid nitrogen and stored at $-80^{\circ} \mathrm{C}$ until further processing. All protocols involving mice were approved by the Dalhousie University Institutional Animal Care and Use Committee.

\subsection{Tissue and cell lysate processing and immunoblotting}

Frozen hearts and gastrocnemius muscle compartment from mice were powdered and homogenized using a tissue homogenizer (Omni TH, Omni International) in ice-cold lysis buffer [containing $20 \mathrm{mM}$ Tris$\mathrm{HCl}$, pH 7.4, 5 mM EDTA, $10 \mathrm{mM} \mathrm{Na} \mathrm{P}_{2} \mathrm{O}_{7}$ (Calbiochem), $100 \mathrm{mM} \mathrm{NaF,} \mathrm{1 \%} \mathrm{Nonidet} \mathrm{P-40,} 2 \mathrm{mM}$ $\mathrm{Na}_{3} \mathrm{VO}_{4}$, protease inhibitor $(10 \mu \mathrm{l} / \mathrm{ml}$; Sigma) and phosphatase inhibitor (10 $\mu \mathrm{l} / \mathrm{ml}$, Calbiochem)]. Homogenate was centrifuged at $1200 \mathrm{~g}$ for $30 \mathrm{~min}$ and the supernatant collected for determining protein concentrations. Cell pellets were sonicated in ice-cold lysis buffer and centrifuged at 16,000 g for $15 \mathrm{~min}$. Protein concentrations of the cell and tissue lysates were determined using BCA protein assay kit (Pierce, Thermo Fisher Scientific). Lysates were subjected to SDS-PAGE and proteins were transferred onto a nitrocellulose membrane (Biorad). Proteins were visualized using a reversible protein stain (Memcode, Pierce, Thermo Fisher Scientific) and membranes were incubated with the following primary antibodies listed in Table S3. Immunoblots were developed using the Western Lightning Plus-ECL enhanced chemiluminescence substrate (Perkin Elmer). Densitometric analysis was performed using Image lab software (Bio-Rad) and the quantifications were normalized by total protein loading using Graph pad software (Clarivate).

\section{5 qPCR analysis}

mRNA levels of BCAA metabolizing enzyme and glucose transporter (Gluts) related gene expression were determined in tissues and cells using qPCR by employing validated optimal reference gene pairs as previously described (93). Primer information of the target and reference genes are provided in Table S4. Powdered tissue and cell pellets were homogenized in Ribozol (Amresco)). RNA was isolated as per the 
manufacturer's instructions, and RNA quality and quantity were examined using a QIAxcel Advanced System (Qiagen). cDNA was synthesized from $1 \mu \mathrm{g}$ of RNA using qScript cDNA supermix (Quanta Biosciences) and cDNA samples were stored at $-30{ }^{\circ} \mathrm{C}$ until further use. $\mathrm{qPCR}$ analysis was performed in 96-well plates using PerfeCTa SYBR green Supermix Low ROX (Thermo Fisher Scientific) and a ViiA7 real-time PCR machine (Thermo Fisher Scientific).

\subsection{AKT activity assay}

AKT activity was measured using the KinaseSTAR AKT activity assay kit (Biovision) as per the manufacturer's instructions. Briefly, $\mathrm{C} 2 \mathrm{C} 12$ cells were plated at a density of $2 \times 10^{6}$ and treated with either $100 \mathrm{nM}$ insulin alone for 15 mins or with $5 \mathrm{mM}$ ketoleucine, ketovaline and ketoisoleucine for 30 mins followed by $100 \mathrm{nM}$ insulin for 15 mins. The cells were lysed using cold kinase extraction buffer and pelleted at $13,000 \mathrm{rpm}$ for $10 \mathrm{mins}$ at $4^{\circ} \mathrm{C}$. One part of the cell lysate was used for assaying protein concentration. $200 \mu \mathrm{g}$ of the cell lysate was incubated with $2 \mu 1$ of AKT antibody and AKT was immunoprecipitated using Protein A- sepharose beads. Kinase assay was performed by incubating the AKT protein-bound beads with $2 \mu \mathrm{l} \mathrm{GSK} 3 \alpha / \mathrm{ATP}$ mixture at $30^{\circ} \mathrm{C}$ for $4 \mathrm{~h}$. The beads were spun down and supernatant collected and boiled in 2X SDS-PAGE loading buffer separated by $12 \%$ SDS-PAGE and analyzed by Western blotting against phosphorylated GSK $3 \alpha$ Ser 21.

\subsection{Sandwich ELISA assay}

AKT phosphorylated at Ser 473 was measured by sandwich ELISA assay using the DuoSet IC ELISA (R\&D systems) as per the manufacturer's protocol. Briefly, C2C12 cells were transduced with either AdCMV-shGFP or Ad-CMV-GFP-rm-shBCKDHA (MOI 200) for $48 \mathrm{~h}$ or treated with DMSO or 500 $\mu$ M BT2 for $20 \mathrm{~h}$, followed by $100 \mathrm{nM}$ insulin treatment for 15 mins. Cells were then solubilized in lysis buffer (1 mM EDTA, 0.5\% Triton X-100, $5 \mathrm{mM} \mathrm{NaF,} 6 \mathrm{M}$ Urea, $1 \mathrm{mM}$ activated $\mathrm{Na}_{3} \mathrm{VO}_{4}, 2.5 \mathrm{mM} \mathrm{Na}_{4} \mathrm{P}_{2} \mathrm{O}_{7}, 10$ $\mu \mathrm{g} / \mathrm{mL}$ Leupeptin, $10 \mu \mathrm{g} / \mathrm{mL}$ Pepstatin, $100 \mu \mathrm{M}$ PMSF, $3.0 \mu \mathrm{g} / \mathrm{mL}$ Aprotinin in PBS, pH 7.2-7.4) at a concentration of $1 \times 10^{7}$ cells $/ \mathrm{ml}$ and centrifuged at $2000 \mathrm{~g}$ for $5 \mathrm{~min}$. One day prior to the assay, a 96 well 
high binding polystyrene plate (Greiner Bio-One) was coated with $6 \mu \mathrm{g} / \mathrm{ml}$ capture antibody (phosphorylated AKT Ser 473) diluted in 1X PBS overnight. For the assay, the supernatant and a sevenpoint standard curve $(100-10000 \mathrm{pg} / \mathrm{ml})$ was diluted 6-fold with diluent 8 (1 mM EDTA, 0.5\% Triton X100, $5 \mathrm{mM} \mathrm{NaF}$ in PBS, pH 7.2-7.4) and further diluted in diluent 3 (1 mM EDTA, 0.5\% Triton X-100, 5 $\mathrm{mM}$ NaF, $1 \mathrm{M}$ Urea in PBS, $\mathrm{pH}$ 7.2-7.4). On the day of the assay, the plate was washed thrice with the wash buffer $\left(0.05 \%\right.$ Tween ${ }^{\circledR} 20$ in PBS, pH 7.2-7.4) and blocked at RT for $2 \mathrm{~h}$ with blocking buffer (1\% BSA, $0.05 \% \mathrm{NaN}_{3}$ in PBS, $\left.\mathrm{pH} 7.2-7.4\right) .100 \mu 1$ of the sample or standard was added per well and incubated at RT for $2 \mathrm{~h}$ followed by aspiration and washing. The samples and standards were then incubated with detection antibody (phosphorylated AKT Ser 473) conjugated with Streptavidin-HRP A at RT for $2 \mathrm{~h}$. Colorimetric reagents were then added, and absorbance measured immediately at $540 \mathrm{~nm}$. The assay was normalized with protein concentration.

\subsection{PP2A Immunoprecipitation phosphatase assay}

$\mathrm{C} 2 \mathrm{C} 12$ cells were treated with either $100 \mathrm{nM}$ insulin for $15 \mathrm{~min}$, or pretreated with $250 \mathrm{nM}$ okadaic acid for 45 mins followed by $100 \mathrm{nM}$ insulin for $15 \mathrm{~min}$, or $5 \mathrm{mM}$ ketoleucine for 30 mins followed by $100 \mathrm{nM}$ insulin for 15 mins, or pretreated with $250 \mathrm{nM}$ okadaic acid for 45 mins followed by $5 \mathrm{mM}$ ketoleucine and $100 \mathrm{nM}$ insulin for 15 mins. Cells were lysed with lysis buffer $(20 \mathrm{mM}$ imidazole-HCl, $2 \mathrm{mM}$ EDTA, $2 \mathrm{mM}$ EGTA, pH 7.0 with $10 \mathrm{mg} / \mathrm{mL}$ each of aprotinin, leupeptin, pepstatin, $1 \mathrm{mM}$ benzamidine and $1 \mathrm{mM}$ PMSF) and $300 \mu \mathrm{g}$ of lysate was used to measure PP2A activity. Tissue was homogenized on ice and centrifuged at $12,000 \mathrm{rpm}$ for 10 minutes at $4{ }^{\circ} \mathrm{C}$. Cells were sonicated before centrifuging similarly. The supernatants were used to assay PP2A phosphatase activity by a standard kit (EMD Millipore) according to the manufacturer's instructions. The intensity of the color reaction was measured at $650 \mathrm{~nm}$ on a Bio-rad microplate spectrophotometer. 


\subsection{PDH activity assay}

C2C12 myotubes were transduced with Ad-mCherry-hBCKDHA (MOI 120) or Ad-GFP-sh-r/mBCKDHA (MOI 200) and their respective controls for $48 \mathrm{~h}$ or treated with $500 \mu \mathrm{M}$ BT2 or DMSO for $20 \mathrm{~h}$ and PDH activity was measured using the PDH activity assay kit (BioVision). Briefly, $1 \times 10^{6}$ cells per condition were lysed with $100 \mu \mathrm{l}$ ice-cold PDH assay buffer and incubated on ice followed by centrifugation at 10,000 rpm for $5 \mathrm{~min} .50 \mu \mathrm{l}$ of the supernatant was used and adjusted with $50 \mu 1 \mathrm{PDH}$ assay buffer and the reaction was started with $50 \mu 1$ of the reaction mixture (PDH assay buffer, PDH developer and PDH substrate) and absorbance was measured immediately at $450 \mathrm{~nm}$ in a kinetic mode for $60 \mathrm{~min}$ at $37^{\circ} \mathrm{C}$ using the Synergy plate reader. NADH standard curve was used to calculate PDH activity in the samples in $\mathrm{mU} / \mathrm{ml}$.

\subsection{Extracellular flux studies}

C2C12 cells were plated at a density of 30,000 cells/per well (XF24 cell culture microplate, Seahorse Biosciences) and differentiated to myotubes for $3 \mathrm{~d}$. Mitostress assay was performed as described in a previous study (92). Briefly, cells were washed with XF Assay media (with $20 \mathrm{mM}$ glucose, $1 \mathrm{mM}$ sodium pyruvate and $1 \mathrm{mM}$ glutamate, without sodium bicarbonate) and incubated for $1 \mathrm{~h}$ at $37^{\circ} \mathrm{C}$ in a non $\mathrm{CO}_{2}$ incubator. $2 \mu \mathrm{M}$ of oligomycin, $1 \mu \mathrm{M}$ of $\mathrm{FCCP}$, and $1 \mu \mathrm{M}$ each of rotenone and antimycin A were injected and oxygen consumption rate (OCR) was measured over $100 \mathrm{~min}$. The assay was normalized to protein content. The analysis was performed using the XFe 2.0.0 software (Seahorse Biosciences).

\subsection{BCKA measurements}

Serum BCKA extraction: $20 \mu \mathrm{l}$ of the sample was combined with $120 \mu \mathrm{l}$ of internal standard (ISTD; $4 \mu \mathrm{g} / \mathrm{ml}$ in $\mathrm{H}_{2} \mathrm{O}$ ) containing leucine-d3 (CDN Isotopes), $40 \mu \mathrm{l}$ of MilliQ water, $60 \mu \mathrm{l}$ of $4 \mathrm{M}$ perchloric acid (VWR) were combined and vortexed. Proteins were precipitated in two sequential steps followed by centrifugation at $13,000 \mathrm{rpm}$ for $15 \mathrm{mins}$ at $4^{\circ} \mathrm{C}$. Supernatant collected from both steps were combined for measuring BCKAs. 
Intracellular BCKA extraction: 500,000 cells, $120 \mathrm{uL}$ of internal standard (ISTD; $4 \mathrm{ug} / \mathrm{ml}$ in $\mathrm{H}_{2} \mathrm{O}$ containing leucine-d3 (CDN Isotopes, D-1973) and $0.8 \mathrm{ng} / \mathrm{uL}$ in $\mathrm{H}_{2} \mathrm{O}$ containing sodium-2-Keto-3-methyl-d3butyrate-3,4,4,4d4 (KIVd7; CDN Isotopes) , $120 \mu 1$ of $6 \mathrm{M}$ perchloric acid (VWR) were combined and homogenized with a tissue homogenizer. Proteins were precipitated in two sequential steps, followed by centrifugation at $16,500 \mathrm{~g}$ for $15 \mathrm{mins}$ at $4^{\circ} \mathrm{C}$. Supernatant collected from both steps were combined and split into two portions for measuring BCKAs. Samples were derivatized according to previously established protocols $(94,95)$.

BCKAs Derivatization and Quantification: $150 \mu \mathrm{L}$ of extract and $500 \mu \mathrm{L}$ of $25 \mathrm{mM}$ OPD in $2 \mathrm{M} \mathrm{HCl}$ (made from o-Phenylenediamine, 98\%; VWR) were combined. The mixture was vortexed and then incubated at $80^{\circ} \mathrm{C}$ for $20 \mathrm{~min}$ followed by incubation on ice for $10 \mathrm{~min}$. The derivatized extract was centrifuged at 500 $\mathrm{g}$ for $15 \mathrm{~min}$ and the supernatant transferred to a tube containing $0.08 \mathrm{~g}$ sodium sulfate (VWR) and $500 \mu \mathrm{l}$ of ethyl acetate (ethyl acetate; VWR) following which they were centrifuged at 500g at RT for $15 \mathrm{~min}$. This step was repeated twice and the supernatant collected were vacuum centrifuged at $30^{\circ} \mathrm{C}$ for 45 min Samples were then reconstituted in $64 \mu \mathrm{L}$ of $200 \mathrm{mM}$ ammonium acetate (made from; ammonium Acetate, 98\%; VWR) and transferred to amber glass UPLC vials (Waters). BCKAs were quantified with a Waters Acquity UPLC, Xevo- $\mu$ Tandem Mass Spectrometer and an Acquity UPLC BEH C18 $(1.7 \mu \mathrm{m}, 2.1 \mathrm{~mm}$ X 50 mm;

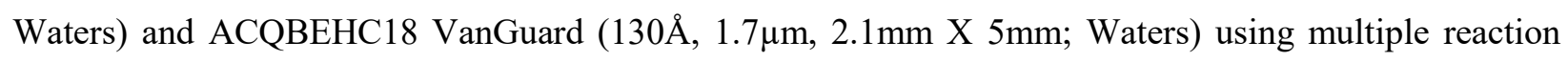
monitoring (MRM) and internal standard calibration as per a prior study (96). 


\section{Figure Legends}

Fig 1. Fasting induces post-translational changes in BCAA catabolic enzymes in the cardiac but not skeletal muscle. a) Study design of C57/BL6 mice ad libitum fed or fasted for $16 \mathrm{hr}$ or refed for $4 \mathrm{hr}$ following fasting, $\mathrm{n}=5$ each group. Quantification of Bckdha, Bckdk, Bcat2, Klf15, Oxct2a, Ivd2, Hmgcs1, Mut mRNA expression corrected to the reference genes, Rpl41/Cyclo in gastrocnemius muscle (b) and Rpl41/Rerl in the heart (c). Immunoblot and densitometric analysis of total and phosphorylated Bckdha E1 $\alpha$ Ser 293 and total Bckdk in the gastrocnemius muscle (d) and heart (e). Statistical analysis was performed using a two-way ANOVA followed by a Tukey's multiple comparison test; ${ }^{*} \mathrm{p}<0,05, * * \mathrm{p}<$ $0.01, * * * * \mathrm{p}<0.0001$ as indicated. f) Palmitate oxidation rate in isolated mice heart ( $\mathrm{n}=3$ per group) perfused aerobically for $30 \mathrm{~min}$ with $5 \mathrm{mM}$ leucine in the presence of $0.8 \mathrm{mM}$ palmitate bound to $2 \%$ fatty acid-free bovine serum albumin and $5 \mathrm{mM}$ glucose. Graph represents mean \pm S.E.M., $\mathrm{n}=3,{ }^{*} \mathrm{p}<0.05$ was performed using Student's t-test.

Fig 2. Diet-induced obesity downregulates BCAA catabolizing enzymes in the skeletal muscle. a) Study design of HFHS diet feeding of C57BL/6 mice at 2, 4, 8 and 13 wk. b) Quantification of Klf15, Mut, Ivd2, Acadm and Hmgcs 1 mRNA expression corrected to Rpl41/Cyclo reference genes in gastrocnemius muscle of 2 wk and 13 wk HFHS fed mice. (c) Quantification of Bckdha, Bckdk, Bcat2, Klf15, Ivd2 and Mut mRNA levels corrected to Rpl41/Rerl reference genes in the heart of 4 wk, 8 wk and 13 wk HFHS fed mice. (d-e) Immunoblot and densitometric analysis of total and phosphorylated and total Bckdha E1 $\alpha$ Ser 293 in gastrocnemius muscle (d) and heart (e). f) Serum BCKAs in 13 wk chow and HFHS diet-fed mice, measured using UPLC MSMS ( $\mathrm{n}=5$ ). Statistical analysis was performed using a two-way ANOVA followed by a Tukey's multiple comparison test; ${ }^{\mathrm{p}}<0,05, * * \mathrm{p}<0.01, * * * * \mathrm{p}<0.0001$ as indicated.

Fig 3. BCKAs impair insulin signaling in $\mathrm{C} 2 \mathrm{C} 12$ cells. (a-c) Differentiated $\mathrm{C} 2 \mathrm{C} 12$ cells were preincubated with either $2 \% \mathrm{BSA}$ or $2 \% \mathrm{BSA}$ conjugated with $0.4 \mathrm{mM}$ palmitate for $16 \mathrm{hr}$ followed by either a) $5 \mathrm{mM}$ ketoleucine, b) ketovaline or c) ketoisoleucine treatment for 30 mins. Myotubes were subjected to $100 \mathrm{nM}$ insulin for 15 mins in presence or absence of individual BCKAs. Immunoblot and densitometric 
analysis of total and phosphorylated AKT Ser 473 and Thr 309, total and phosphorylated IRS Tyr 612. Statistical analysis was performed using a two-way ANOVA followed by a Tukey's multiple comparison test; ${ }^{*} \mathrm{p}<0.05,{ }^{* *} \mathrm{p}<0.01, * * * * \mathrm{p}<0.0001$ as indicated; *within groups, \#between groups. d) Quantification of insulin-induced AKT activity in C2C12 myotubes following $100 \mathrm{nM}$ insulin stimulation for $15 \mathrm{mins}$ in the presence or absence of 5mM BCKAs treated for 30 mins. Non-insulin, non- BCKAs treated cells served as controls. The graph represents mean \pm S.E.M., $n=3, * p<0.05$ was performed using Student's t-test.

Fig 4. BCKAs impair insulin signaling in cardiomyocytes. a) Schematic of isolation of neonatal (NRCM) and adult (ARCM) rat cardiomyocytes and the treatment protocol. b) NRCMs and c) ARCMs were preincubated with either $2 \% \mathrm{BSA}$ or $2 \%$ BSA conjugated with $0.4 \mathrm{mM}$ palmitate for $16 \mathrm{hr}$ followed by $5 \mathrm{mM}$ ketoleucine for $30 \mathrm{~min}$. Immunoblot and densitometric analysis of total and phosphorylated AKT Ser 473 levels in cardiomyocytes subjected to either $200 \mathrm{nM}$ (NRCMs) or $100 \mathrm{nM}$ (ARCMs) insulin stimulation for 20 mins in the presence or absence of ketoleucine. Statistical analysis was performed using a two-way ANOVA followed by a Tukey's multiple comparison test; $* \mathrm{p}<0,05, * * \mathrm{p}<0.01, * * * * \mathrm{p}<0.0001$ as indicated; *within groups, \#between groups.

Fig 5. Okadaic acid rescue BCKAs induced insulin signaling impairment. a) Outline of the treatment scheme used to test the effect of okadaic acid on ketoleucine mediated insulin signaling. b) PP2A activity expressed as percent mean control and c) immunoblot and densitometric analysis of total to phosphorylated AKT Ser 473 and total to phosphorylated AKT2 Ser 474 in differentiated C2C12 myotubes pretreated with 250nM okadaic acid (OA) for 30 mins followed by $5 \mathrm{mM}$ ketoleucine for 30 mins and 100nM insulin stimulation for 15 mins. No insulin-treated cells were employed as controls. Other relevant groups are provided as an illustration in (a). Statistical analysis was performed using a one-way ANOVA followed by a Tukey's multiple comparison test; ${ }^{*} \mathrm{p}<0,05, * * \mathrm{p}<0.01, * * * * \mathrm{p}<0.0001$ as indicated; *comparison with -INS, \#comparison with +INS, ^comparison between +KL+INS v/s OA+KL+INS, @+KL+INS v/s OA+INS. . 
Fig 6. Modulating intracellular BCKAs by modifying BCAA catabolic enzyme expression alters skeletal and cardiac muscle insulin signaling. a) Brief schematic of enzymes regulating BCKA catabolism. b) UPLC mass spectrometric analysis of intracellular BCKAs levels in C2C12 myotubes transduced with Ad-CMV-GFP-hBCKDK/HA (MOI 150) or Ad-CMV-mCherry-hBCKDHA/Flag (MOI 150) and their appropriate controls. The graph represents mean \pm S.E.M., $n=3, * p<0.05$ was performed using Student's t-test. Immunoblot and densitometric analysis of total and phosphorylated AKT Ser 473, Thr 308 and total and phosphorylated AKT2 Ser 474 in (c) C2C12 myotubes transduced with Ad-CMVGFP or Ad-CMV-GFP-hBCKDK/HA, (d) Ad-CMV-mCherry or Ad-CMV-mCherry-hBCKDHA/Flag, (e) Ad-CMV-shGFP or Ad-CMV-shGFP-r/mBCKDHA (MOI 200) for $48 \mathrm{hr}$ followed by incubation with $100 \mathrm{nM}$ insulin for 15 mins. Statistical analysis was performed using a two-way ANOVA followed by a Tukey's multiple comparison test; ${ }^{*} \mathrm{p}<0,05, * * \mathrm{p}<0.01, * * * * \mathrm{p}<0.0001$ as indicated; *within groups, \#between groups.

Fig 7. Pharmacological inhibition of BCKDK by BT2 improves muscle insulin signaling. a) A diagrammatic representation of BT2 action. b) Intracellular BCKAs by UPLC/MS-MS and c) qPCR analysis of BCAA catabolic genes Bckdha, Bckdk, Bcat2, Hadh, Hibch and Klf15 corrected to Rer1/Rpl7 reference gene levels in $\mathrm{C} 2 \mathrm{C} 12$ myotubes treated with $500 \mu \mathrm{M}$ and $750 \mu \mathrm{M}$ BT2 for $20 \mathrm{hr}$. d) Immunoblot analysis and densitometric quantification of phosphorylated BCKDH subunit E1 at Ser 293 in C2C12 myotubes treated with $160 \mu \mathrm{M}, 250 \mu \mathrm{M}, 320 \mu \mathrm{M}, 500 \mu \mathrm{M}$ and $750 \mu \mathrm{M}$ BT2 for $20 \mathrm{hr}$. e) Immunoblotting and densitometric quantification of phosphorylated AKT Ser 473 and total AKT in differentiated C2C12 cells pretreated with $320 \mu \mathrm{M}, 500 \mu \mathrm{M}$ and $750 \mu \mathrm{M}$ BT2 for $20 \mathrm{hr}$ followed by incubation with $100 \mathrm{nM}$ insulin for 15 mins. (f) Immunoblot analysis and densitometric quantification of phosphorylated AKT Ser 473, Ser 474 and total AKT1 and AKT2 in C2C12 myoblasts transduced with Ad-CMV-shGFP or Ad-CMV-shGFPr/mBCKDHA (MOI 200) for $48 \mathrm{hr}$ followed by incubation with $500 \mu \mathrm{M}$ BT2 for $20 \mathrm{hr}$ and stimulation with 100nM insulin for 15 mins. Statistical analysis was performed using a two-way ANOVA followed by a Tukey's multiple comparison test; ${ }^{*} \mathrm{p}<0,05, * * \mathrm{p}<0.01, * * * * \mathrm{p}<0.0001$ as indicated; *within groups, 
\#comparison with shGFP+INS, ^ comparison with shBCKDHA+BT2.g) qPCR analysis of Glut1 and Glut4 mRNA levels corrected to Rer1/Rp17 reference gene levels in $\mathrm{C} 2 \mathrm{C} 12$ myotubes treated with or without $500 \mu \mathrm{M}$ BT2 for $20 \mathrm{hr}$. h) PDH activity analyzed in differentiated $\mathrm{C} 2 \mathrm{C} 12$ myotubes preincubated with $500 \mu \mathrm{M}$ BT2 for $20 \mathrm{hr}$, followed by $100 \mathrm{nM}$ insulin treatment for $15 \mathrm{mins}$. Statistical analysis was performed using a one-way ANOVA followed by a Tukey's multiple comparison test; ${ }^{*} \mathrm{p}<0,05,{ }^{*} \mathrm{p}<0.01$, **** $\mathrm{p}$ $<0.0001$ as indicated; * comparison with -INS, ^ comparison with $+\mathrm{BT} 2 .{ }^{14} \mathrm{C}$-palmitate oxidation expressed as i) trapped ${ }^{14} \mathrm{CO}_{2}$ or (j) acid-soluble metabolite in $\mathrm{C} 2 \mathrm{C} 12$ myotubes treated with or without $500 \mu \mathrm{M}$ BT2 for $20 \mathrm{hr}$. The graph represents mean \pm S.E.M., $\mathrm{n}=3,{ }^{*} \mathrm{p}<0.05$ was performed using Student's t-test.

Fig 8. BCKAs activate mTORC1 and downstream protein translation signaling in skeletal muscle. a)

Schematic of mTORC1 signaling and its downstream protein translational targets. b) C2C12 myotubes were treated with 5mM ketoleucine, ketoisoleucine and ketovaline for 45 mins. b-c) Immunoblot analysis and densitometric quantification of total and phosphorylated mTORC1 Ser 2448, p70S6K Thr 389, eEF2 Thr 56, eIFG Ser 1108 in C2C12 myotubes transduced with Ad-CMV-shGFP or Ad-CMV-shGFP$\mathrm{r} / \mathrm{mBCKDHA}$ for $48 \mathrm{hr}$ followed by stimulation with $100 \mathrm{nM}$ insulin for $15 \mathrm{mins}$. Statistical analysis was performed using a two-way ANOVA followed by a Tukey's multiple comparison test; ${ }^{*} \mathrm{p}<0,05,{ }^{*}$ p $<$ $0.01, * * * * \mathrm{p}<0.0001$ as indicated; *within groups, \#between groups. d) Graphical abstract. BCAA catabolic enzyme expression in the gastrocnemius muscles is downregulated with progressive DIO increasing circulating BCKAs (a). Exogenous supply of BCKAs results in impairment of insulin induced AKT phosphorylation by blunting insulin induced PP2A inactivation (b) and decreasing IRS1 phosphorylation. Increased accumulation of intracellular BCKAs by adenoviral overexpression of BCKDK or silencing BCKDH also impairs insulin-induced AKT phosphorylation (c) by activating mTORC1 (d) also resulting in activation of key signaling components of the protein translation machinery. Alternatively, genetic and pharmacological activation of BCKDHA reduces intracellular BCKAs and sensitizes cells to insulin signaling (e) and function (f). Finally, BT2 treatment increases FAO and reduces incomplete FAO (g) further explaining its insulin-sensitizing effects. 


\section{Declaration}

\section{Funding \& Acknowledgement}

This work was supported by Natural Sciences and Engineering Research Council of Canada (RGPIN-201403687), Diabetes Canada (NOD_OG-3-15-5037-TP \& NOD_SC-5-16-5054-TP) and New Brunswick Health Research Foundation grants to T.P.; D.B., was funded by postdoctoral fellowships from New Brunswick Health Research Foundation and Dalhousie Medicine New Brunswick.

\section{Conflict of Interest}

The authors declare no conflict of interest.

\section{Availability of data and materials}

All data and materials used in the current study are available from the corresponding author upon request.

\section{Consent for publication}

Not applicable 


\section{References}

1. de la, O. V., Zazpe, I., and Ruiz-Canela, M. (2020) Effect of branched-chain amino acid supplementation, dietary intake and circulating levels in cardiometabolic diseases: an updated review. Current opinion in clinical nutrition and metabolic care 23, 35-50

2. Jang, C., Oh, S. F., Wada, S., Rowe, G. C., Liu, L., Chan, M. C., Rhee, J., Hoshino, A., Kim, B., Ibrahim, A., Baca, L. G., Kim, E., Ghosh, C. C., Parikh, S. M., Jiang, A., Chu, Q., Forman, D. E., Lecker, S. H., Krishnaiah, S., Rabinowitz, J. D., Weljie, A. M., Baur, J. A., Kasper, D. L., and Arany, Z. (2016) A branched-chain amino acid metabolite drives vascular fatty acid transport and causes insulin resistance. Nature medicine 22, 421-426

3. Kimball, S. R., and Jefferson, L. S. (2006) Signaling pathways and molecular mechanisms through which branched-chain amino acids mediate translational control of protein synthesis. The Journal of nutrition 136, 227S-231S

4. Lu, G., Ren, S., Korge, P., Choi, J., Dong, Y., Weiss, J., Koehler, C., Chen, J. N., and Wang, Y. (2007) A novel mitochondrial matrix serine/threonine protein phosphatase regulates the mitochondria permeability transition pore and is essential for cellular survival and development. Genes \& development 21, 784-796

5. Nair, K. S., and Short, K. R. (2005) Hormonal and signaling role of branched-chain amino acids. The Journal of nutrition 135, 1547S-1552S

6. Neinast, M., Murashige, D., and Arany, Z. (2019) Branched Chain Amino Acids. Annual review of physiology 81, 139-164

7. Harris, R. A., Joshi, M., and Jeoung, N. H. (2004) Mechanisms responsible for regulation of branched-chain amino acid catabolism. Biochem Biophys Res Commun 313, 391-396

8. Nair, K. S., and Short, K. R. (2005) Hormonal and signaling role of branched-chain amino acids. The Journal of nutrition 135, 1547S-1552S

9. Kimball, S. R., and Jefferson, L. S. (2006) Signaling pathways and molecular mechanisms through which branched-chain amino acids mediate translational control of protein synthesis. The Journal of nutrition 136, 227S-231S

10. Lu, G., Sun, H., She, P., Youn, J. Y., Warburton, S., Ping, P., Vondriska, T. M., Cai, H., Lynch, C. J., and Wang, Y. (2009) Protein phosphatase $2 \mathrm{Cm}$ is a critical regulator of branched-chain amino acid catabolism in mice and cultured cells. $J$ Clin Invest 119, 1678-1687

11. Sun, H., Olson, K. C., Gao, C., Prosdocimo, D. A., Zhou, M., Wang, Z., Jeyaraj, D., Youn, J. Y., Ren, S., Liu, Y., Rau, C. D., Shah, S., Ilkayeva, O., Gui, W. J., William, N. S., Wynn, R. M., Newgard, C. B., Cai, H., Xiao, X., Chuang, D. T., Schulze, P. C., Lynch, C., Jain, M. K., and Wang, Y. (2016) Catabolic Defect of Branched-Chain Amino Acids Promotes Heart Failure. Circulation 133, 2038-2049

12. Gray, S., Feinberg, M. W., Hull, S., Kuo, C. T., Watanabe, M., Sen-Banerjee, S., DePina, A., Haspel, R., and Jain, M. K. (2002) The Kruppel-like factor KLF15 regulates the insulin-sensitive glucose transporter GLUT4. The Journal of biological chemistry 277, 34322-34328

13. Prosdocimo, D. A., Anand, P., Liao, X., Zhu, H., Shelkay, S., Artero-Calderon, P., Zhang, L., Kirsh, J., Moore, D., Rosca, M. G., Vazquez, E., Kerner, J., Akat, K. M., Williams, Z., Zhao, J., Fujioka, H., Tuschl, T., Bai, X., Schulze, P. C., Hoppel, C. L., Jain, M. K., and Haldar, S. M. (2014) Kruppellike factor 15 is a critical regulator of cardiac lipid metabolism. The Journal of biological chemistry 289, 5914-5924

14. Prosdocimo, D. A., John, J. E., Zhang, L., Efraim, E. S., Zhang, R., Liao, X., and Jain, M. K. (2015) KLF15 and PPARalpha Cooperate to Regulate Cardiomyocyte Lipid Gene Expression and Oxidation. PPAR research 2015, 201625

15. Ericksen, R. E., Lim, S. L., McDonnell, E., Shuen, W. H., Vadiveloo, M., White, P. J., Ding, Z., Kwok, R., Lee, P., Radda, G. K., Toh, H. C., Hirschey, M. D., and Han, W. (2019) Loss of BCAA 
Catabolism during Carcinogenesis Enhances mTORC1 Activity and Promotes Tumor Development and Progression. Cell metabolism 29, 1151-1165 e1156

16. Silva, L. S., Poschet, G., Nonnenmacher, Y., Becker, H. M., Sapcariu, S., Gaupel, A. C., Schlotter, M., Wu, Y., Kneisel, N., Seiffert, M., Hell, R., Hiller, K., Lichter, P., and Radlwimmer, B. (2017) Branched-chain ketoacids secreted by glioblastoma cells via MCT1 modulate macrophage phenotype. EMBO reports 18, 2172-2185

17. Newgard, C. B., An, J., Bain, J. R., Muehlbauer, M. J., Stevens, R. D., Lien, L. F., Haqq, A. M., Shah, S. H., Arlotto, M., Slentz, C. A., Rochon, J., Gallup, D., Ilkayeva, O., Wenner, B. R., Yancy, W. S., Jr., Eisenson, H., Musante, G., Surwit, R. S., Millington, D. S., Butler, M. D., and Svetkey, L. P. (2009) A branched-chain amino acid-related metabolic signature that differentiates obese and lean humans and contributes to insulin resistance. Cell metabolism 9, 311-326

18. Trico, D., Prinsen, H., Giannini, C., de Graaf, R., Juchem, C., Li, F., Caprio, S., Santoro, N., and Herzog, R. I. (2017) Elevated alpha-Hydroxybutyrate and Branched-Chain Amino Acid Levels Predict Deterioration of Glycemic Control in Adolescents. The Journal of clinical endocrinology and metabolism 102, 2473-2481

19. Wang, T. J., Larson, M. G., Vasan, R. S., Cheng, S., Rhee, E. P., McCabe, E., Lewis, G. D., Fox, C. S., Jacques, P. F., Fernandez, C., O'Donnell, C. J., Carr, S. A., Mootha, V. K., Florez, J. C., Souza, A., Melander, O., Clish, C. B., and Gerszten, R. E. (2011) Metabolite profiles and the risk of developing diabetes. Nature medicine 17, 448-453

20. Li, T., Zhang, Z., Kolwicz, S. C., Jr., Abell, L., Roe, N. D., Kim, M., Zhou, B., Cao, Y., Ritterhoff, J., Gu, H., Raftery, D., Sun, H., and Tian, R. (2017) Defective Branched-Chain Amino Acid Catabolism Disrupts Glucose Metabolism and Sensitizes the Heart to Ischemia-Reperfusion Injury. Cell metabolism 25, 374-385

21. Fillmore, N., Wagg, C. S., Zhang, L., Fukushima, A., and Lopaschuk, G. D. (2018) Cardiac branched-chain amino acid oxidation is reduced during insulin resistance in the heart. American journal of physiology. Endocrinology and metabolism 315, E1046-E1052

22. Uddin, G. M., Zhang, L., Shah, S., Fukushima, A., Wagg, C. S., Gopal, K., Al Batran, R., Pherwani, S., Ho, K. L., Boisvenue, J., Karwi, Q. G., Altamimi, T., Wishart, D. S., Dyck, J. R. B., Ussher, J. R., Oudit, G. Y., and Lopaschuk, G. D. (2019) Impaired branched chain amino acid oxidation contributes to cardiac insulin resistance in heart failure. Cardiovascular diabetology 18, 86

23. Carnagarin, R., Dharmarajan, A. M., and Dass, C. R. (2015) Molecular aspects of glucose homeostasis in skeletal muscle--A focus on the molecular mechanisms of insulin resistance. Molecular and cellular endocrinology 417, 52-62

24. DeFronzo, R. A., and Tripathy, D. (2009) Skeletal muscle insulin resistance is the primary defect in type 2 diabetes. Diabetes care 32 Suppl 2, S157-163

25. Biswas, D., Duffley, L., and Pulinilkunnil, T. (2019) Role of branched-chain amino acidcatabolizing enzymes in intertissue signaling, metabolic remodeling, and energy homeostasis. FASEB journal : official publication of the Federation of American Societies for Experimental Biology 33, 8711-8731

26. Zhou, M., Shao, J., Wu, C. Y., Shu, L., Dong, W., Liu, Y., Chen, M., Wynn, R. M., Wang, J., Wang, J., Gui, W. J., Qi, X., Lusis, A. J., Li, Z., Wang, W., Ning, G., Yang, X., Chuang, D. T., Wang, Y., and Sun, H. (2019) Targeting BCAA Catabolism to Treat Obesity-Associated Insulin Resistance. Diabetes 68, 1730-1746

27. Renguet, E., Ginion, A., Gelinas, R., Bultot, L., Auquier, J., Robillard Frayne, I., Daneault, C., Vanoverschelde, J. L., Des Rosiers, C., Hue, L., Horman, S., Beauloye, C., and Bertrand, L. (2017) Metabolism and acetylation contribute to leucine-mediated inhibition of cardiac glucose uptake. American journal of physiology. Heart and circulatory physiology 313, H432-H445

28. Goldberg, E. J., Buddo, K. A., McLaughlin, K. L., Fernandez, R. F., Pereyra, A. S., Psaltis, C. E., Lin, C. T., Hagen, J. T., Boykov, I. N., Nguyen, T. K., Gowdy, K. M., Ellis, J. M., Neufer, P. D., McClung, J. M., and Fisher-Wellman, K. H. (2019) Tissue-specific characterization of 
mitochondrial branched-chain keto acid oxidation using a multiplexed assay platform. The Biochemical journal 476, 1521-1537

29. Adeva, M. M., Calvino, J., Souto, G., and Donapetry, C. (2012) Insulin resistance and the metabolism of branched-chain amino acids in humans. Amino acids 43, 171-181

30. Grimsrud, P. A., Carson, J. J., Hebert, A. S., Hubler, S. L., Niemi, N. M., Bailey, D. J., Jochem, A., Stapleton, D. S., Keller, M. P., Westphall, M. S., Yandell, B. S., Attie, A. D., Coon, J. J., and Pagliarini, D. J. (2012) A quantitative map of the liver mitochondrial phosphoproteome reveals posttranslational control of ketogenesis. Cell metabolism 16, 672-683

31. McGarry, J. D., and Foster, D. W. (1980) Regulation of hepatic fatty acid oxidation and ketone body production. Annual review of biochemistry 49, 395-420

32. Lerin, C., Goldfine, A. B., Boes, T., Liu, M., Kasif, S., Dreyfuss, J. M., De Sousa-Coelho, A. L., Daher, G., Manoli, I., Sysol, J. R., Isganaitis, E., Jessen, N., Goodyear, L. J., Beebe, K., Gall, W., Venditti, C. P., and Patti, M. E. (2016) Defects in muscle branched-chain amino acid oxidation contribute to impaired lipid metabolism. Molecular metabolism 5, 926-936

33. Newgard, C. B. (2012) Interplay between lipids and branched-chain amino acids in development of insulin resistance. Cell metabolism 15, 606-614

34. Menni, C., Fauman, E., Erte, I., Perry, J. R., Kastenmuller, G., Shin, S. Y., Petersen, A. K., Hyde, C., Psatha, M., Ward, K. J., Yuan, W., Milburn, M., Palmer, C. N., Frayling, T. M., Trimmer, J., Bell, J. T., Gieger, C., Mohney, R. P., Brosnan, M. J., Suhre, K., Soranzo, N., and Spector, T. D. (2013) Biomarkers for type 2 diabetes and impaired fasting glucose using a nontargeted metabolomics approach. Diabetes 62, 4270-4276

35. She, P., Olson, K. C., Kadota, Y., Inukai, A., Shimomura, Y., Hoppel, C. L., Adams, S. H., Kawamata, Y., Matsumoto, H., Sakai, R., Lang, C. H., and Lynch, C. J. (2013) Leucine and protein metabolism in obese Zucker rats. PloS one 8, e59443

36. Holecek, M., and Micuda, S. (2017) Amino acid concentrations and protein metabolism of two types of rat skeletal muscle in postprandial state and after brief starvation. Physiological research 66, 959-967

37. Nie, C., He, T., Zhang, W., Zhang, G., and Ma, X. (2018) Branched Chain Amino Acids: Beyond Nutrition Metabolism. International journal of molecular sciences 19

38. Junttila, M. R., Li, S. P., and Westermarck, J. (2008) Phosphatase-mediated crosstalk between MAPK signaling pathways in the regulation of cell survival. FASEB journal : official publication of the Federation of American Societies for Experimental Biology 22, 954-965

39. Cazzolli, R., Carpenter, L., Biden, T. J., and Schmitz-Peiffer, C. (2001) A role for protein phosphatase 2A-like activity, but not atypical protein kinase Czeta, in the inhibition of protein kinase B/Akt and glycogen synthesis by palmitate. Diabetes 50, 2210-2218

40. Ugi, S., Imamura, T., Maegawa, H., Egawa, K., Yoshizaki, T., Shi, K., Obata, T., Ebina, Y., Kashiwagi, A., and Olefsky, J. M. (2004) Protein phosphatase 2A negatively regulates insulin's metabolic signaling pathway by inhibiting Akt (protein kinase B) activity in 3T3-L1 adipocytes. Molecular and cellular biology 24, 8778-8789

41. Mandavia, C., and Sowers, J. R. (2012) Phosphoprotein Phosphatase PP2A Regulation of Insulin Receptor Substrate 1 and Insulin Metabolic Signaling. Cardiorenal medicine 2, 308-313

42. Hwang, B., Jeoung, N. H., and Harris, R. A. (2009) Pyruvate dehydrogenase kinase isoenzyme 4 (PDHK4) deficiency attenuates the long-term negative effects of a high-saturated fat diet. The Biochemical journal 423, 243-252

43. Jeoung, N. H., and Harris, R. A. (2008) Pyruvate dehydrogenase kinase-4 deficiency lowers blood glucose and improves glucose tolerance in diet-induced obese mice. American journal of physiology. Endocrinology and metabolism 295, E46-54

44. Jeoung, N. H., Rahimi, Y., Wu, P., Lee, W. N., and Harris, R. A. (2012) Fasting induces ketoacidosis and hypothermia in PDHK2/PDHK4-double-knockout mice. The Biochemical journal 443, 829-839 
45. Koves, T. R., Ussher, J. R., Noland, R. C., Slentz, D., Mosedale, M., Ilkayeva, O., Bain, J., Stevens, R., Dyck, J. R., Newgard, C. B., Lopaschuk, G. D., and Muoio, D. M. (2008) Mitochondrial overload and incomplete fatty acid oxidation contribute to skeletal muscle insulin resistance. Cell metabolism 7, 45-56

46. Lopaschuk, G. D. (2016) Fatty Acid Oxidation and Its Relation with Insulin Resistance and Associated Disorders. Annals of nutrition \& metabolism 68 Suppl 3, 15-20

47. White, P. J., McGarrah, R. W., Grimsrud, P. A., Tso, S. C., Yang, W. H., Haldeman, J. M., GrenierLarouche, T., An, J., Lapworth, A. L., Astapova, I., Hannou, S. A., George, T., Arlotto, M., Olson, L. B., Lai, M., Zhang, G. F., Ilkayeva, O., Herman, M. A., Wynn, R. M., Chuang, D. T., and Newgard, C. B. (2018) The BCKDH Kinase and Phosphatase Integrate BCAA and Lipid Metabolism via Regulation of ATP-Citrate Lyase. Cell metabolism 27, 1281-1293 e1287

48. Jeganathan, S., Abdullahi, A., Zargar, S., Maeda, N., Riddell, M. C., and Adegoke, O. A. (2014) Amino acid-induced impairment of insulin sensitivity in healthy and obese rats is reversible. Physiological reports 2

49. Lynch, C. J. (2001) Role of leucine in the regulation of mTOR by amino acids: revelations from structure-activity studies. The Journal of nutrition 131, 861S-865S

50. Siddik, M. A. B., and Shin, A. C. (2019) Recent Progress on Branched-Chain Amino Acids in Obesity, Diabetes, and Beyond. Endocrinology and metabolism 34, 234-246

51. Son, S. M., Park, S. J., Lee, H., Siddiqi, F., Lee, J. E., Menzies, F. M., and Rubinsztein, D. C. (2019) Leucine Signals to mTORC1 via Its Metabolite Acetyl-Coenzyme A. Cell metabolism 29, 192-201 e197

52. Gran, P., and Cameron-Smith, D. (2011) The actions of exogenous leucine on mTOR signalling and amino acid transporters in human myotubes. BMC physiology 11, 10

53. Wolfson, R. L., Chantranupong, L., Saxton, R. A., Shen, K., Scaria, S. M., Cantor, J. R., and Sabatini, D. M. (2016) Sestrin2 is a leucine sensor for the mTORC1 pathway. Science 351, 43-48

54. Ong, P. S., Wang, L. Z., Dai, X., Tseng, S. H., Loo, S. J., and Sethi, G. (2016) Judicious Toggling of mTOR Activity to Combat Insulin Resistance and Cancer: Current Evidence and Perspectives. Frontiers in pharmacology 7, 395

55. Wang, X., Regufe da Mota, S., Liu, R., Moore, C. E., Xie, J., Lanucara, F., Agarwala, U., Pyr Dit Ruys, S., Vertommen, D., Rider, M. H., Eyers, C. E., and Proud, C. G. (2014) Eukaryotic elongation factor 2 kinase activity is controlled by multiple inputs from oncogenic signaling. Molecular and cellular biology 34, 4088-4103

56. Vary, T. C., Deiter, G., and Lynch, C. J. (2007) Rapamycin limits formation of active eukaryotic initiation factor $4 \mathrm{~F}$ complex following meal feeding in rat hearts. The Journal of nutrition 137, 1857-1862

57. Shenton, D., Smirnova, J. B., Selley, J. N., Carroll, K., Hubbard, S. J., Pavitt, G. D., Ashe, M. P., and Grant, C. M. (2006) Global translational responses to oxidative stress impact upon multiple levels of protein synthesis. The Journal of biological chemistry 281, 29011-29021

58. Topf, U., Suppanz, I., Samluk, L., Wrobel, L., Boser, A., Sakowska, P., Knapp, B., Pietrzyk, M. K., Chacinska, A., and Warscheid, B. (2018) Quantitative proteomics identifies redox switches for global translation modulation by mitochondrially produced reactive oxygen species. Nature communications $\mathbf{9}, 324$

59. Schieke, S. M., Phillips, D., McCoy, J. P., Jr., Aponte, A. M., Shen, R. F., Balaban, R. S., and Finkel, T. (2006) The mammalian target of rapamycin (mTOR) pathway regulates mitochondrial oxygen consumption and oxidative capacity. The Journal of biological chemistry 281, 2764327652

60. Lee, C. C., Watkins, S. M., Lorenzo, C., Wagenknecht, L. E., Il'yasova, D., Chen, Y. D., Haffner, S. M., and Hanley, A. J. (2016) Branched-Chain Amino Acids and Insulin Metabolism: The Insulin Resistance Atherosclerosis Study (IRAS). Diabetes care 39, 582-588 
61. Zhao, X., Han, Q., Liu, Y., Sun, C., Gang, X., and Wang, G. (2016) The Relationship between Branched-Chain Amino Acid Related Metabolomic Signature and Insulin Resistance: A Systematic Review. Journal of diabetes research 2016, 2794591

62. Kadota, Y., Toyoda, T., Kitaura, Y., Adams, S. H., and Shimomura, Y. (2013) Regulation of hepatic branched-chain alpha-ketoacid dehydrogenase complex in rats fed a high-fat diet. Obesity research \& clinical practice 7 , e439-444

63. Sailer, M., Dahlhoff, C., Giesbertz, P., Eidens, M. K., de Wit, N., Rubio-Aliaga, I., Boekschoten, M. V., Muller, M., and Daniel, H. (2013) Increased plasma citrulline in mice marks diet-induced obesity and may predict the development of the metabolic syndrome. PloS one 8, e63950

64. Sansbury, B. E., Bhatnagar, A., and Hill, B. G. (2014) Impact of nutrient excess and endothelial nitric oxide synthase on the plasma metabolite profile in mice. Frontiers in physiology 5, 453

65. Piccolo, B. D., Graham, J. L., Stanhope, K. L., Fiehn, O., Havel, P. J., and Adams, S. H. (2016) Plasma amino acid and metabolite signatures tracking diabetes progression in the UCD-T2DM rat model. American journal of physiology. Endocrinology and metabolism 310, E958-969

66. Wiklund, P., Zhang, X., Pekkala, S., Autio, R., Kong, L., Yang, Y., Keinanen-Kiukaanniemi, S., Alen, M., and Cheng, S. (2016) Insulin resistance is associated with altered amino acid metabolism and adipose tissue dysfunction in normoglycemic women. Scientific reports 6, 24540

67. Green, C. R., Wallace, M., Divakaruni, A. S., Phillips, S. A., Murphy, A. N., Ciaraldi, T. P., and Metallo, C. M. (2016) Branched-chain amino acid catabolism fuels adipocyte differentiation and lipogenesis. Nature chemical biology 12, 15-21

68. Neinast, M. D., Jang, C., Hui, S., Murashige, D. S., Chu, Q., Morscher, R. J., Li, X., Zhan, L., White, E., Anthony, T. G., Rabinowitz, J. D., and Arany, Z. (2019) Quantitative Analysis of the Whole-Body Metabolic Fate of Branched-Chain Amino Acids. Cell metabolism 29, 417-429 e414

69. Hernandez-Alvarez, M. I., Diaz-Ramos, A., Berdasco, M., Cobb, J., Planet, E., Cooper, D., Pazderska, A., Wanic, K., O'Hanlon, D., Gomez, A., de la Ballina, L. R., Esteller, M., Palacin, M., O'Gorman, D. J., Nolan, J. J., and Zorzano, A. (2017) Early-onset and classical forms of type 2 diabetes show impaired expression of genes involved in muscle branched-chain amino acids metabolism. Scientific reports 7, 13850

70. Lian, K., Du, C., Liu, Y., Zhu, D., Yan, W., Zhang, H., Hong, Z., Liu, P., Zhang, L., Pei, H., Zhang, J., Gao, C., Xin, C., Cheng, H., Xiong, L., and Tao, L. (2015) Impaired adiponectin signaling contributes to disturbed catabolism of branched-chain amino acids in diabetic mice. Diabetes $\mathbf{6 4}$, 49-59

71. Yee, N. S., and Shargel, L. (1986) Effect of cimetidine or ranitidine pretreatment on hepatic mixed function oxidase activity in the rat. Drug metabolism and disposition: the biological fate of chemicals 14, 580-584

72. Harper, A. E., Miller, R. H., and Block, K. P. (1984) Branched-chain amino acid metabolism. Annual review of nutrition 4, 409-454

73. Badoud, F., Lam, K. P., DiBattista, A., Perreault, M., Zulyniak, M. A., Cattrysse, B., Stephenson, S., Britz-McKibbin, P., and Mutch, D. M. (2014) Serum and adipose tissue amino acid homeostasis in the metabolically healthy obese. Journal of proteome research 13, 3455-3466

74. Boulet, M. M., Chevrier, G., Grenier-Larouche, T., Pelletier, M., Nadeau, M., Scarpa, J., Prehn, C., Marette, A., Adamski, J., and Tchernof, A. (2015) Alterations of plasma metabolite profiles related to adipose tissue distribution and cardiometabolic risk. American journal of physiology. Endocrinology and metabolism 309, E736-746

75. Serralde-Zuniga, A. E., Guevara-Cruz, M., Tovar, A. R., Herrera-Hernandez, M. F., Noriega, L. G., Granados, O., and Torres, N. (2014) Omental adipose tissue gene expression, gene variants, branched-chain amino acids, and their relationship with metabolic syndrome and insulin resistance in humans. Genes \& nutrition 9, 431

76. Gannon, N. P., Schnuck, J. K., and Vaughan, R. A. (2018) BCAA Metabolism and Insulin Sensitivity - Dysregulated by Metabolic Status? Molecular nutrition \& food research 62, e1700756 
77. Wang, J., Liu, Y., Lian, K., Shentu, X., Fang, J., Shao, J., Chen, M., Wang, Y., Zhou, M., and Sun, H. (2019) BCAA Catabolic Defect Alters Glucose Metabolism in Lean Mice. Frontiers in physiology 10, 1140

78. Golam S.; ... Ussher J. R.; Lopaschuk G. D., (2019) A Cardiac Specific Branched Chain Aminotransferase Deletion Increases Insulin Stimulated Glucose Oxidation in the Mouse Heart. Circulation Research 125, Suppl_1

79. Moghei, M., Tavajohi-Fini, P., Beatty, B., and Adegoke, O. A. (2016) Ketoisocaproic acid, a metabolite of leucine, suppresses insulin-stimulated glucose transport in skeletal muscle cells in a BCAT2-dependent manner. American journal of physiology. Cell physiology 311, C518-527

80. McGarrah, R. W., Zhang, G. F., Christopher, B. A., Deleye, Y., Walejko, J. M., Page, S., Ilkayeva, O., White, P. J., and Newgard, C. B. (2020) Dietary branched-chain amino acid restriction alters fuel selection and reduces triglyceride stores in hearts of Zucker fatty rats. American journal of physiology. Endocrinology and metabolism 318, E216-E223

81. She, P., Reid, T. M., Bronson, S. K., Vary, T. C., Hajnal, A., Lynch, C. J., and Hutson, S. M. (2007) Disruption of BCATm in mice leads to increased energy expenditure associated with the activation of a futile protein turnover cycle. Cell metabolism 6, 181-194

82. Kearney, A. L., Cooke, K. C., Norris, D. M., Zadoorian, A., Krycer, J. R., Fazakerley, D. J., Burchfield, J. G., and James, D. E. (2019) Serine 474 phosphorylation is essential for maximal Akt2 kinase activity in adipocytes. The Journal of biological chemistry 294, 16729-16739

83. Oppenheim, R. D., Creek, D. J., Macrae, J. I., Modrzynska, K. K., Pino, P., Limenitakis, J., Polonais, V., Seeber, F., Barrett, M. P., Billker, O., McConville, M. J., and Soldati-Favre, D. (2014) $\mathrm{BCKDH}$ : the missing link in apicomplexan mitochondrial metabolism is required for full virulence of Toxoplasma gondii and Plasmodium berghei. PLoS pathogens 10, e1004263

84. Small, L., Brandon, A. E., Quek, L. E., Krycer, J. R., James, D. E., Turner, N., and Cooney, G. J. (2018) Acute activation of pyruvate dehydrogenase increases glucose oxidation in muscle without changing glucose uptake. American journal of physiology. Endocrinology and metabolism 315, E258-E266

85. Shao, D., Villet, O., Zhang, Z., Choi, S. W., Yan, J., Ritterhoff, J., Gu, H., Djukovic, D., Christodoulou, D., Kolwicz, S. C., Jr., Raftery, D., and Tian, R. (2018) Glucose promotes cell growth by suppressing branched-chain amino acid degradation. Nature communications 9, 2935

86. Yoon, M. S. (2017) The Role of Mammalian Target of Rapamycin (mTOR) in Insulin Signaling. Nutrients 9

87. Bertrand, L., Horman, S., Beauloye, C., and Vanoverschelde, J. L. (2008) Insulin signalling in the heart. Cardiovascular research 79, 238-248

88. Trivedi, P. C., Bartlett, J. J., Perez, L. J., Brunt, K. R., Legare, J. F., Hassan, A., Kienesberger, P. C., and Pulinilkunnil, T. (2016) Glucolipotoxicity diminishes cardiomyocyte TFEB and inhibits lysosomal autophagy during obesity and diabetes. Biochimica et biophysica acta 1861, 1893-1910

89. Fuchs, C. J., Hermans, W. J. H., Holwerda, A. M., Smeets, J. S. J., Senden, J. M., van Kranenburg, J., Gijsen, A. P., Wodzig, W., Schierbeek, H., Verdijk, L. B., and van Loon, L. J. C. (2019) Branched-chain amino acid and branched-chain ketoacid ingestion increases muscle protein synthesis rates in vivo in older adults: a double-blind, randomized trial. The American journal of clinical nutrition 110, 862-872

90. Fonseca, B. D., Smith, E. M., Yelle, N., Alain, T., Bushell, M., and Pause, A. (2014) The everevolving role of mTOR in translation. Seminars in cell \& developmental biology 36, 102-112

91. Guo, X., Huang, C., Lian, K., Wang, S., Zhao, H., Yan, F., Zhang, X., Zhang, J., Xie, H., An, R., and Tao, L. (2016) BCKA down-regulates mTORC2-Akt signal and enhances apoptosis susceptibility in cardiomyocytes. Biochemical and biophysical research communications 480, 106113 
92. Biswas, D., Ghosh, M., Kumar, S., and Chakrabarti, P. (2016) PPARalpha-ATGL pathway improves muscle mitochondrial metabolism: implication in aging. FASEB journal : official publication of the Federation of American Societies for Experimental Biology 30, 3822-3834

93. Perez, L. J., Rios, L., Trivedi, P., D'Souza, K., Cowie, A., Nzirorera, C., Webster, D., Brunt, K., Legare, J. F., Hassan, A., Kienesberger, P. C., and Pulinilkunnil, T. (2017) Validation of optimal reference genes for quantitative real time PCR in muscle and adipose tissue for obesity and diabetes research. Scientific reports 7, 3612

94. Armenta, J. M., Cortes, D. F., Pisciotta, J. M., Shuman, J. L., Blakeslee, K., Rasoloson, D., Ogunbiyi, O., Sullivan, D. J., Jr., and Shulaev, V. (2010) Sensitive and rapid method for amino acid quantitation in malaria biological samples using AccQ.Tag ultra performance liquid chromatography-electrospray ionization-MS/MS with multiple reaction monitoring. Analytical chemistry 82, 548-558

95. Salazar, C., Armenta, J. M., Cortes, D. F., and Shulaev, V. (2012) Combination of an AccQ.Tagultra performance liquid chromatographic method with tandem mass spectrometry for the analysis of amino acids. Methods in molecular biology 828, 13-28

96. Kand'ar, R., Zakova, P., Jirosova, J., and Sladka, M. (2009) Determination of branched chain amino acids, methionine, phenylalanine, tyrosine and alpha-keto acids in plasma and dried blood samples using HPLC with fluorescence detection. Clinical chemistry and laboratory medicine 47, 565-572 
B

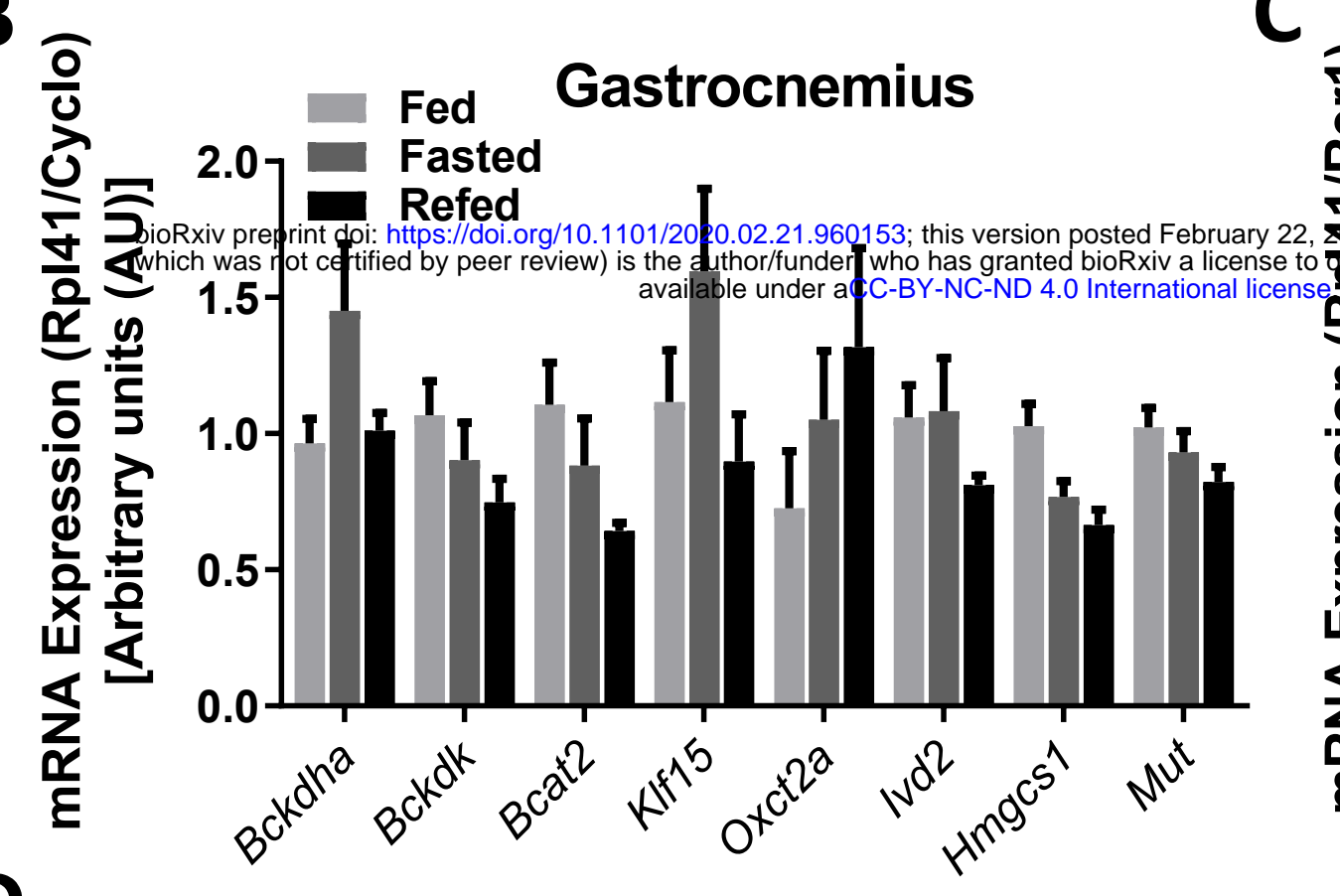

Blood Glucose

Liver Weight

Ventricle Weight

Protein and Gene

Expression Analysis

D

Gastroc

Fed

Fasted

Refed

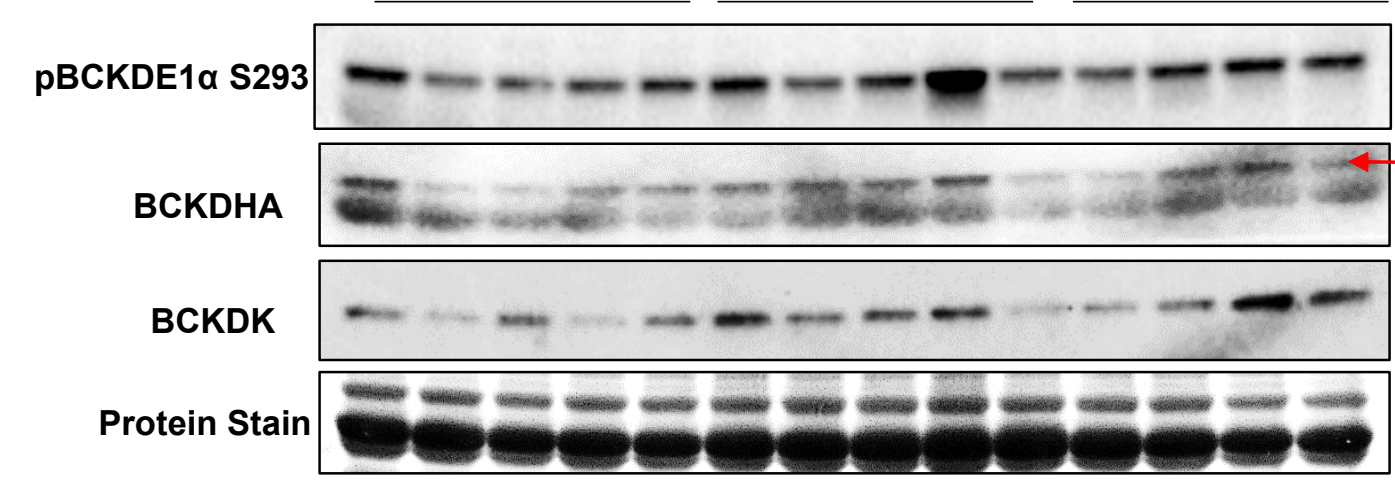

E

Heart

Fed

Fasted

Refed

pBCKDE1a S293 $\rightarrow--------\cdots$

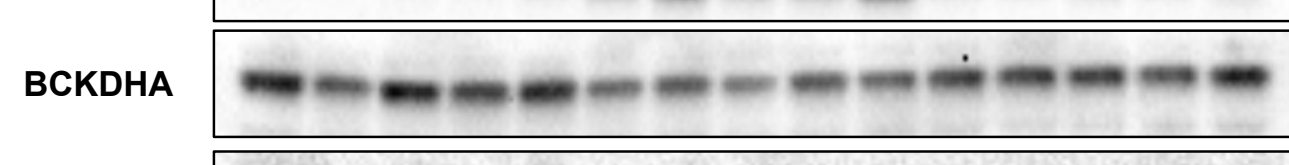

BCKDK

Protein Stain

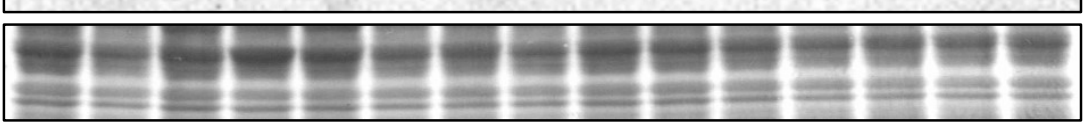

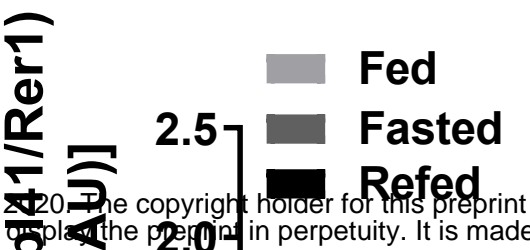

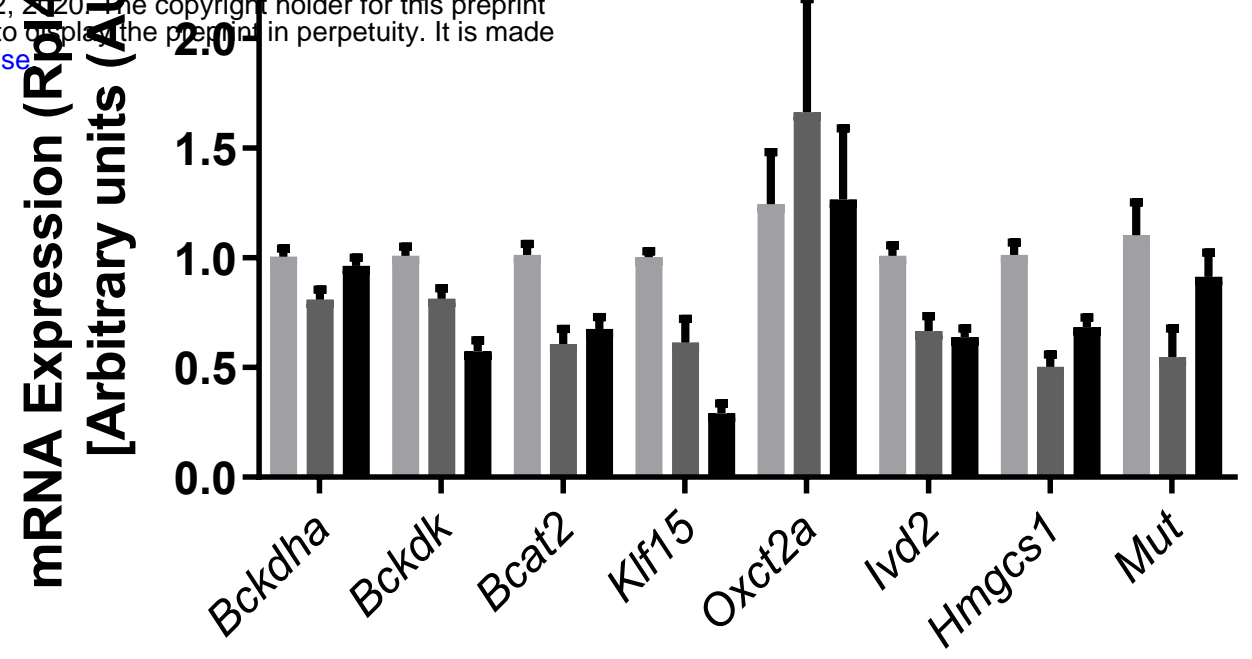

Heart
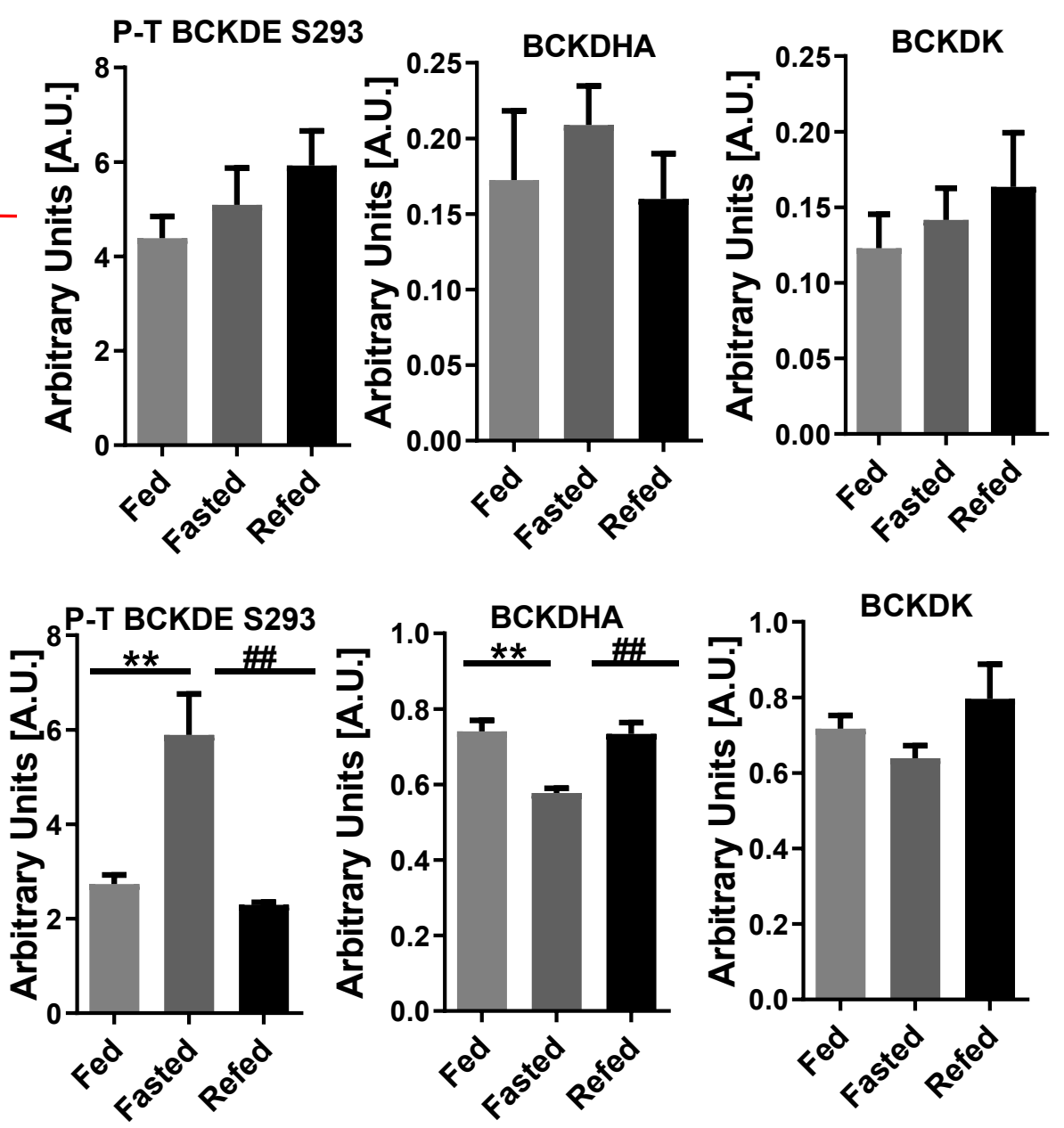

F

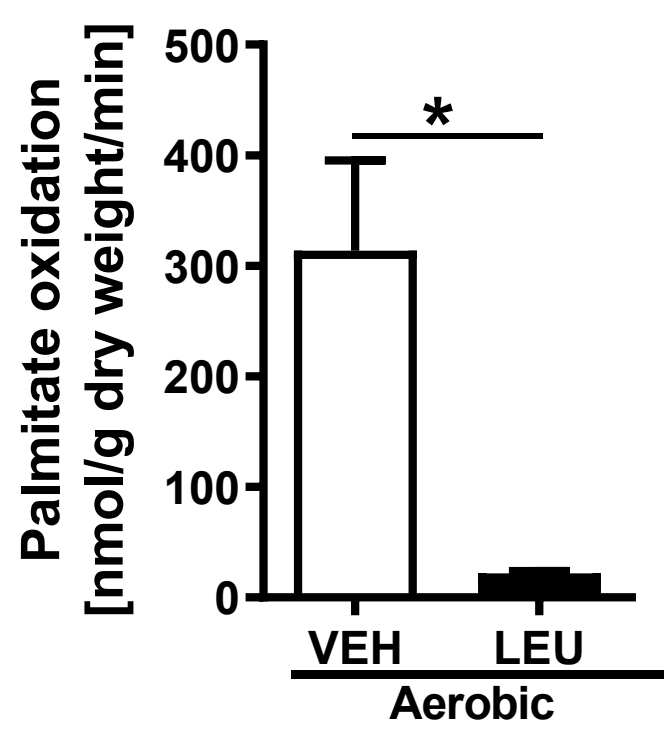


A

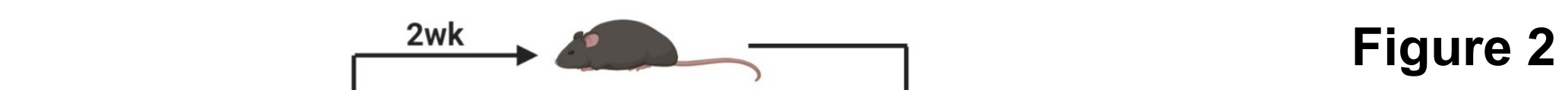

B

bioRxiv preprint doi: https://dojorg/101101/2020.02.21.960153; this version posted February 22, 2020. The copyright holder for this preprint

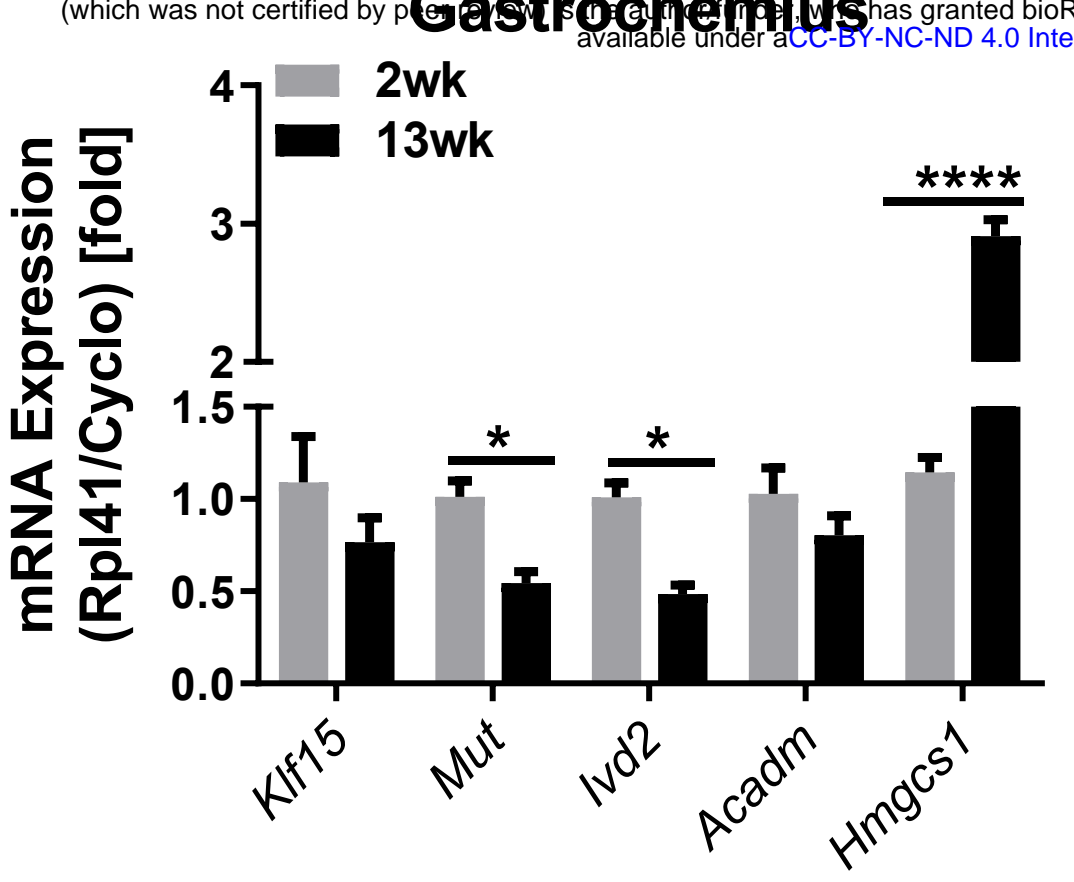

D
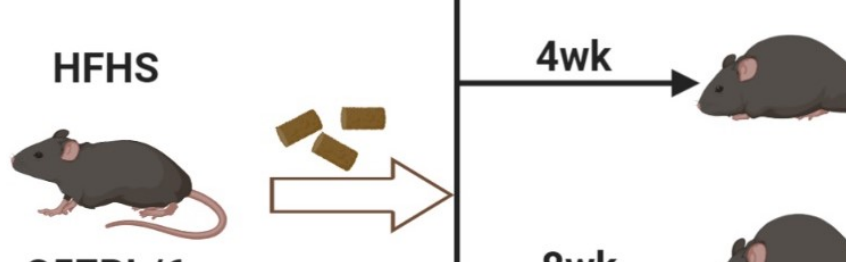

Protein and

mRNA expression

analysis

Serum BCKAs

analysis

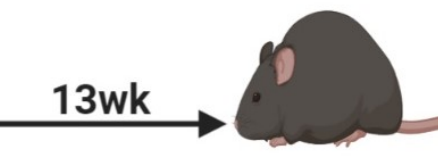

Cense.

Heart

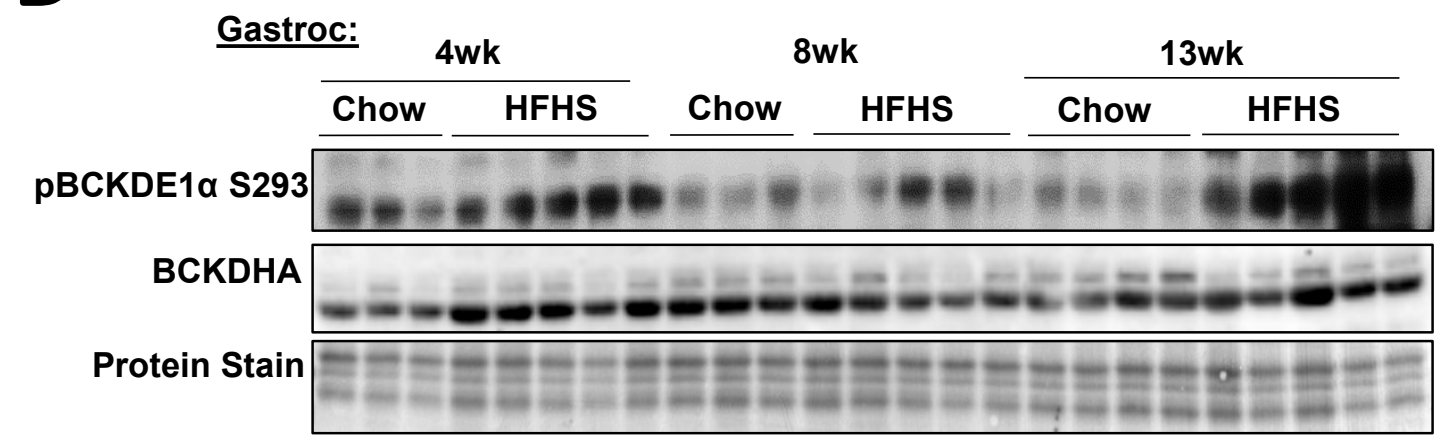

$E$

Heart:

4wk 8wk

$13 w k$

p
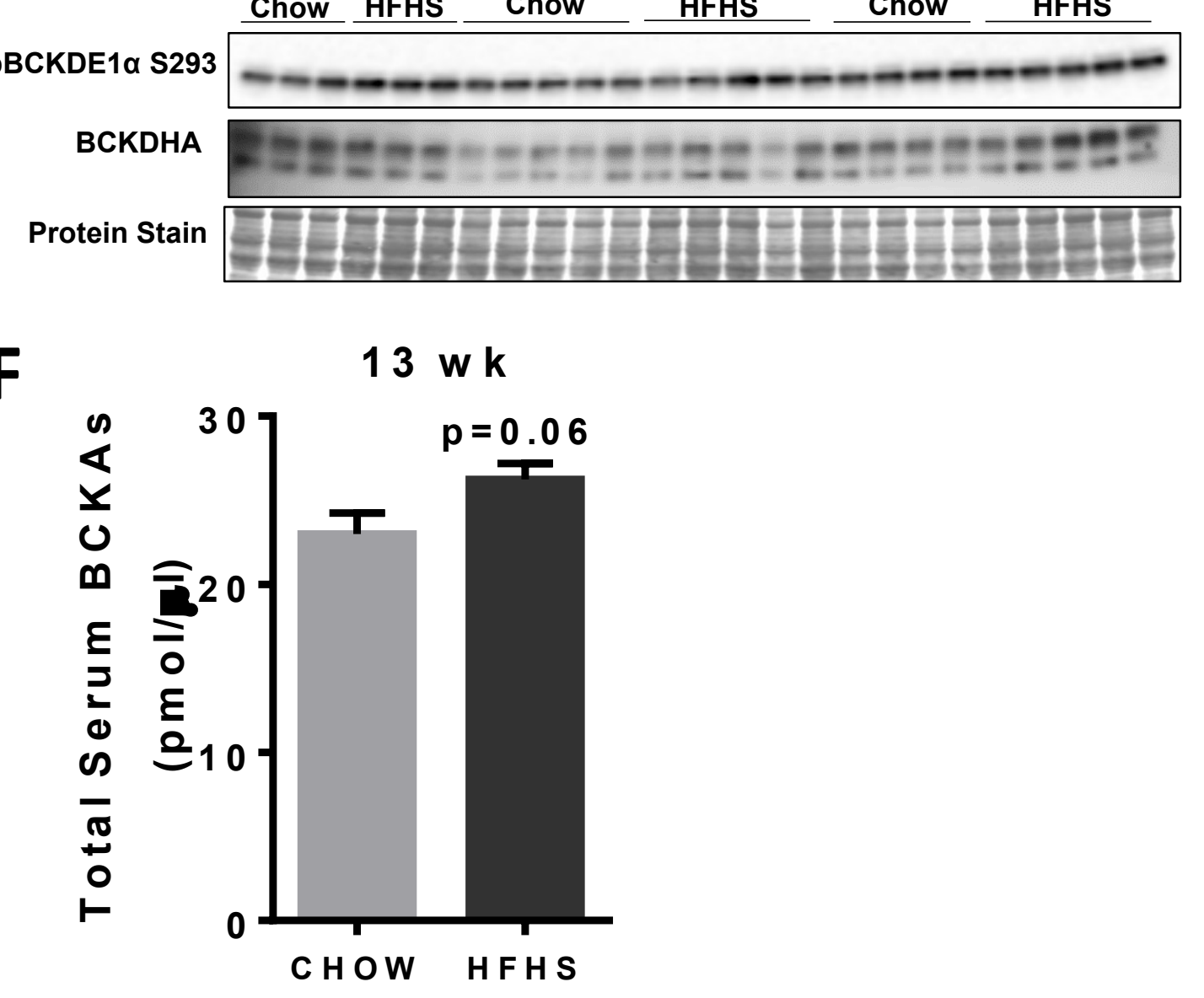
KLEU

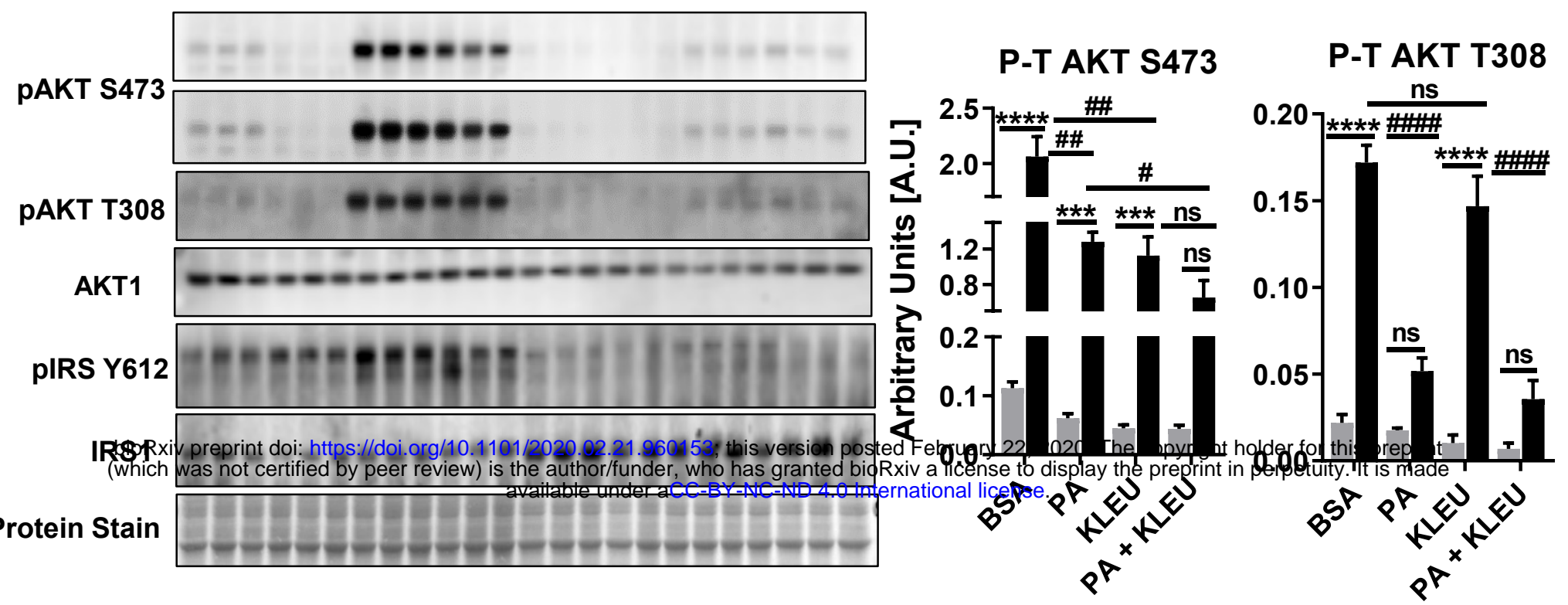

B

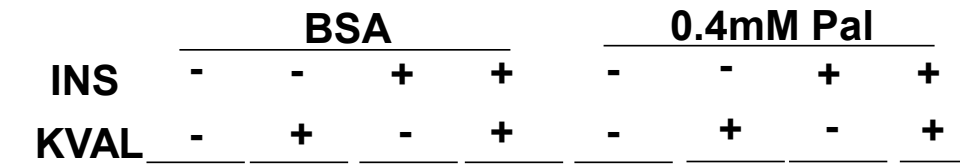

pAKT S473

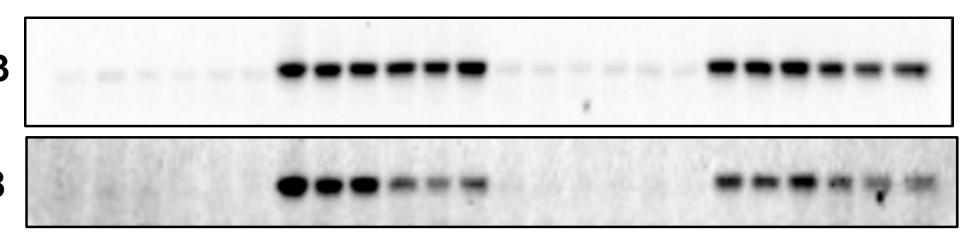

AKT1

pIRS Y612

IRS1

Protein Stain
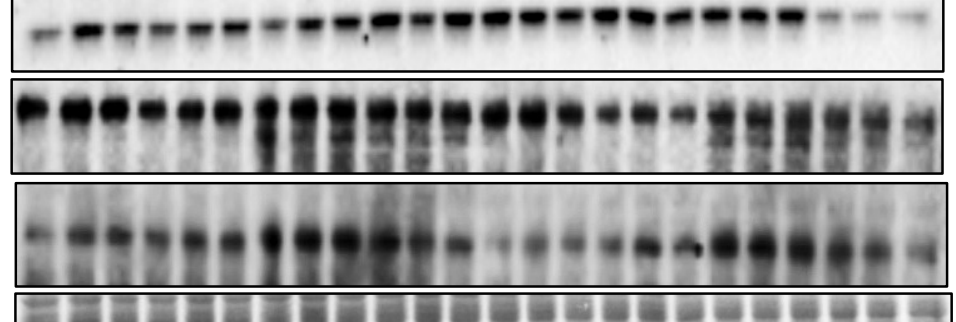

C
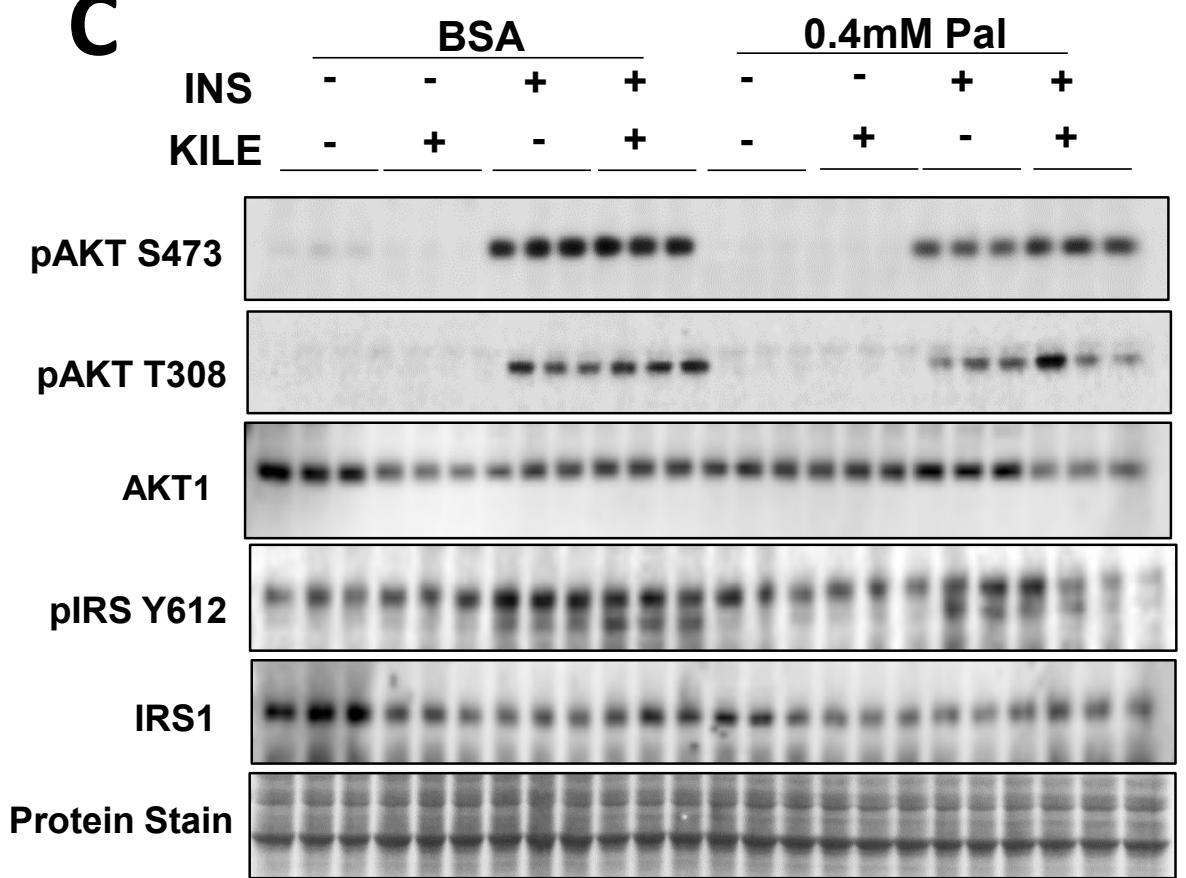

P-T AKT S473
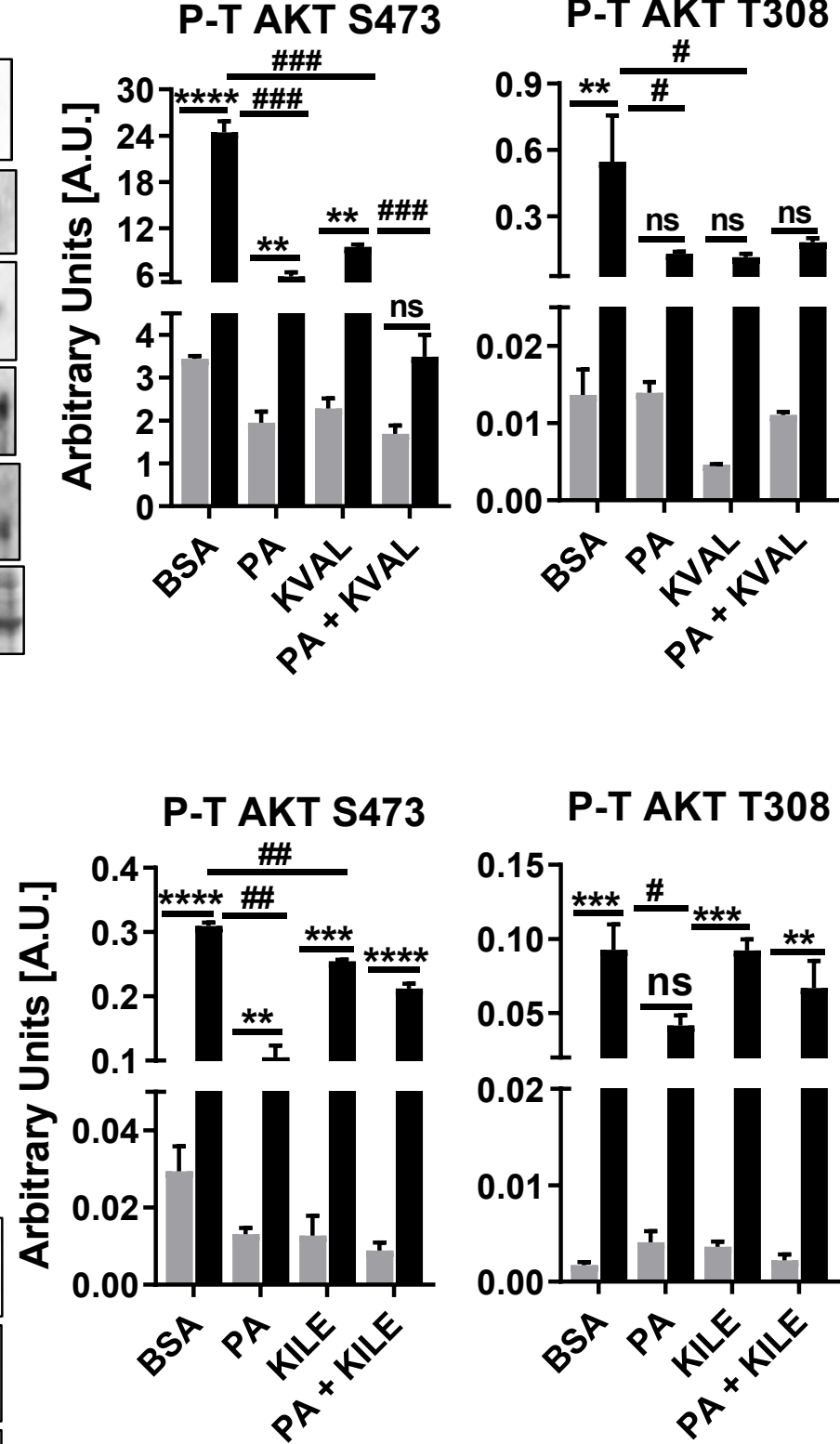

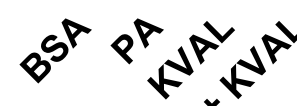

$p^{x}$
P-T IRS Y612

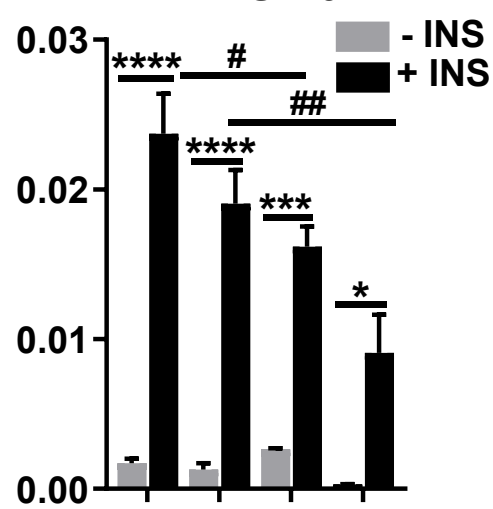

$\beta_{s p} b_{p}+p_{p}$

$p^{p}$

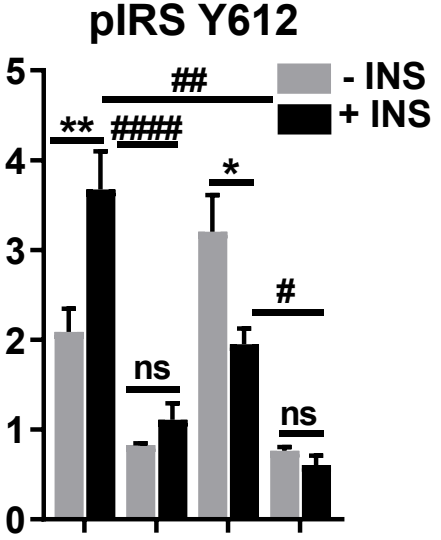

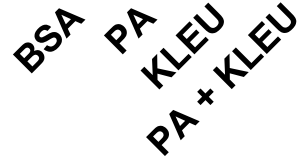

P-T AKT S473

P-T AKT T308
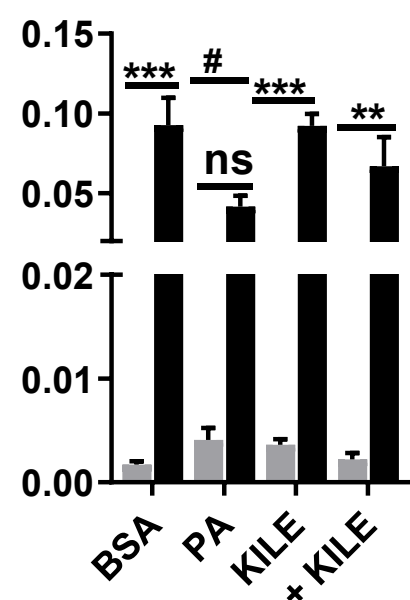

$p^{p}$

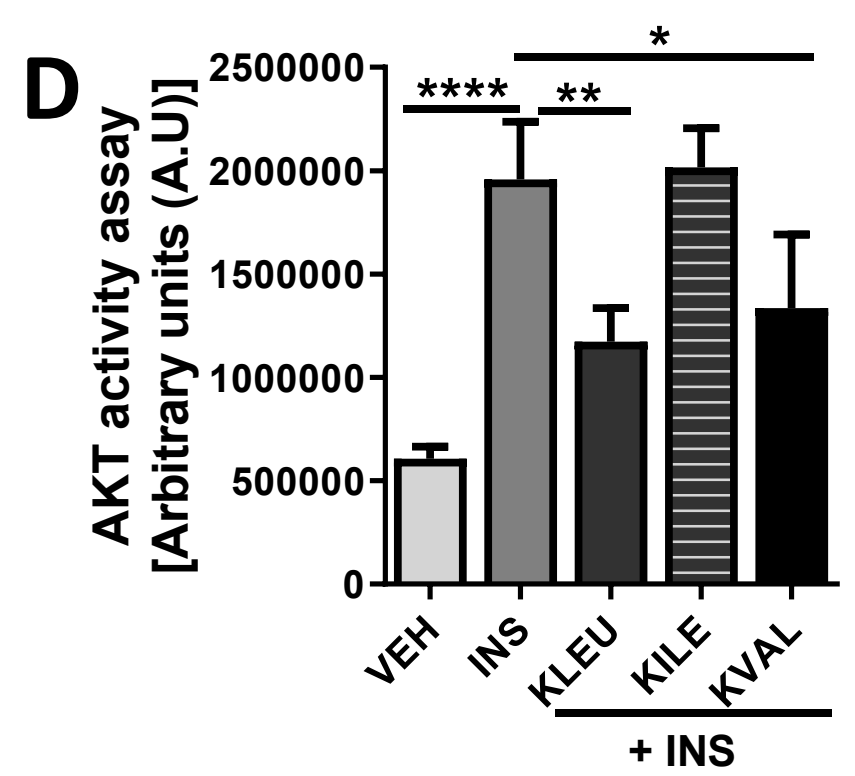

P-T IRS Y612

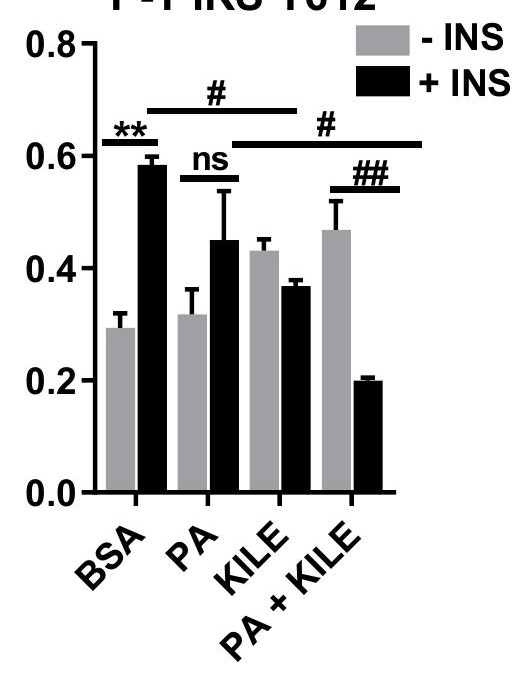




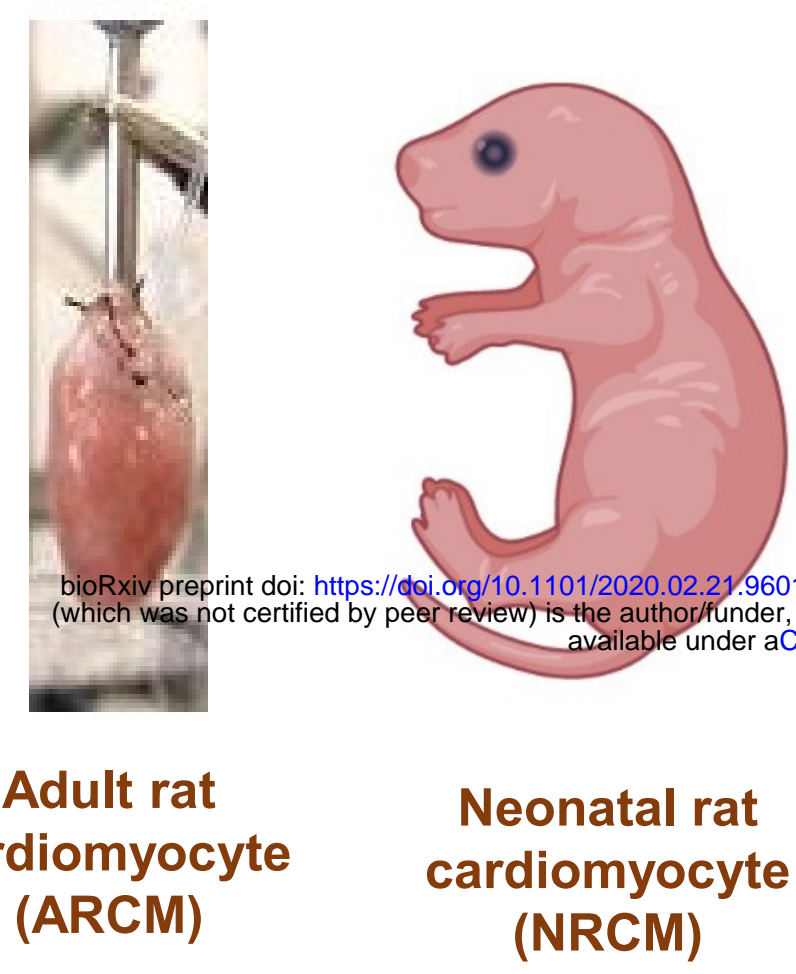

Cardiomyocyte isolation

Treatment with $0.4 \mathrm{mM}$ BSA conjugated $\mathrm{Na}$ -

Palmitate, 16 hrs
Adult rat
cardiomyocyte
(ARCM)
Neonatal rat
(NRCM)

Treatment with $100 \mathrm{nM}$ insulin, 15mins
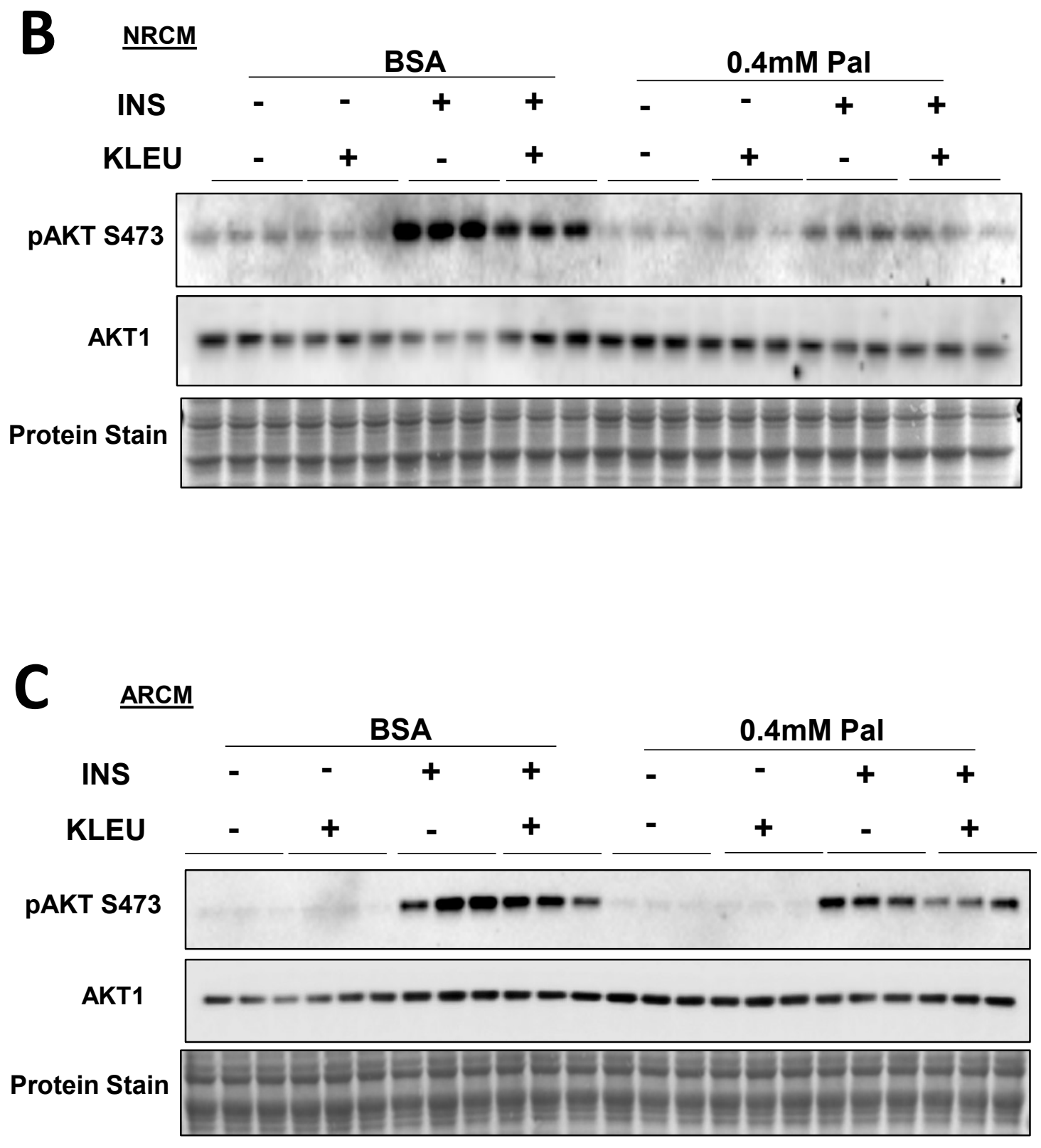

Pretreatment with 5mM ketoleucine, 30 mins 
A

$\rightarrow$ Treated with appropriate

vehicle controls

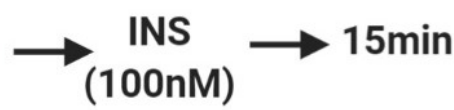

bioRxivpreaprint Kabi: Elt which was not certified py peer review) is the author/funddepolagnàs granted bioRxiv a license to display the preprint in perpetulty. It is made

$\underset{(250 \mathrm{nM})}{\mathrm{OA}} \rightarrow 30 \mathrm{~min} \rightarrow \underset{(100 \mathrm{nM})}{\mathrm{INS}} \rightarrow 15 \mathrm{~min}$

$\underset{(250 \mathrm{nM})}{\rightarrow} \rightarrow 30 \mathrm{~min} \rightarrow \begin{gathered}\mathrm{KLEU} \\ (5 \mathrm{mM})\end{gathered} \rightarrow 30 \mathrm{~min} \rightarrow \underset{(100 \mathrm{nM})}{\mathrm{KLEU}+\mathrm{INS}} \rightarrow 15 \mathrm{~min}$

B
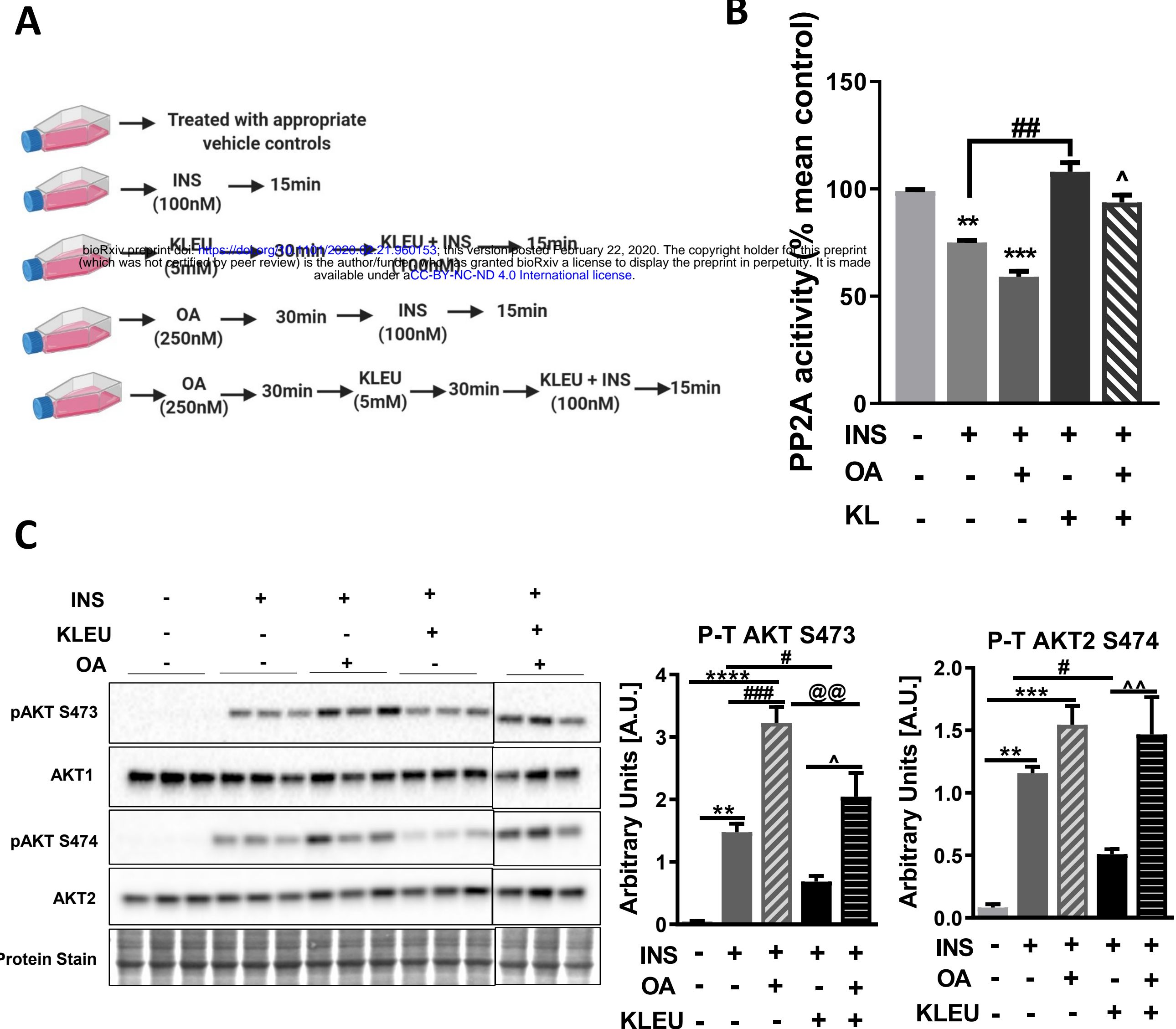
